\title{
Comparing the Temporal Development of Wheat Spike Blast Epidemics in a Region of Bolivia Where the Disease Is Endemic
}

\author{
Karasi B. Mills, ${ }^{1}$ Jorge D. Salgado, ${ }^{1}$ Christian D. Cruz, ${ }^{2}$ Barbara Valent, ${ }^{3}$ Laurence V. Madden, ${ }^{1}$ and Pierce A. Paul ${ }^{1, \dagger}$ \\ ${ }^{1}$ Department of Plant Pathology, The Ohio State University, Ohio Agricultural Research and Development Center, Wooster, OH 44691 \\ ${ }^{2}$ Department of Botany and Plant Pathology, Purdue University, West Lafayette, IN 47907 \\ ${ }^{3}$ Department of Plant Pathology, Kansas State University, Manhattan, KS 66506
}

\begin{abstract}
Epidemics of wheat blast, caused the Triticum pathotype of Magnaporthe oryzae, were studied in the Santa Cruz del la Sierra region of Bolivia to quantify and compare the temporal dynamics of the disease under different growing conditions. Six plots of a susceptible wheat cultivar were planted at Cuatro Cañadas (CC), Okinawa 1 (OK1), and Okinawa 2 (OK2) in 2015. Spike blast incidence (INC) and severity (SEV) and leaf blast severity (LEAF) were quantified in each plot at regular intervals on a $10 \times 10$ grid $(n=100$ clusters of spikes), beginning at head emergence (Feekes growth stage 10.5), for a total of nine assessments at CC, six at OK1, and six at OK2. Spike blast increased over time for 20 to 30 days before approaching a mean INC of $100 \%$ and a mean SEV of 60 to $75 \%$.

major rain events. Estimated $y_{0}$ values (initial blast intensity) were significantly $(P<0.05)$ higher at $\mathrm{OK} 1$ than at $\mathrm{CC}$ or $\mathrm{OK} 2$, whereas $r_{\mathrm{L}}$ values (the logistic rate parameter) were significantly higher at $\mathrm{OK} 2$ than at $\mathrm{CC}$ or OK1. It took about 10 fewer days for SEV to reach 10,15 , or $20 \%$ at OK1 compared with OK2 and CC. Based on survival analyses, the survivor functions for time to 10,15 and $20 \%$ SEV (ts) were significantly different between OK1 and the other locations, with the probabilities of SEV reaching the thresholds being highest at OK1. LEAF at 21 days after Feekes 10.5 had a significant effect on $t$ s at OK1. For every $5 \%$ increase in LEAF, the chance of SEV reaching the thresholds by day 21 increased by 30 to $55 \%$.
\end{abstract} The logistic model was the most appropriate for describing the temporal dynamics of spike blast. The highest absolute rates of disease increase occurred earliest at $\mathrm{OK} 1$ and latest at $\mathrm{OK} 2$, and in all cases it coincided with
Keywords: cereals and grains, climate and weather effects, disease development and spread, epidemiology, field crops, fungi
Wheat blast, caused by the Triticum pathotype of the fungus Magnaporthe oryzae (MoT), is a disease that affects leaves, spikes, and other aboveground parts of the wheat plant (Urashima 2010). MoT can infect leaves throughout the growing season, causing oblong lesions with dark edges and centers that are light gray during sporulation and straw-colored thereafter (Cruz and Valent 2017; GongoraCanul et al. 2020; Igarashi 1990; Igarashi et al. 1986; Lima 2004). However, damage to the spike is often more conspicuous, extensive, and of greater concern from a yield loss standpoint (Cruz and Valent 2017; Kohli et al. 2011). Under favorable conditions for infection and disease development $\left(25\right.$ to $30^{\circ} \mathrm{C}$ with 24 to $48 \mathrm{~h}$ of leaf wetness or high RH [Cardoso et al. 2008; Mills et al. 2020]), spike blast symptoms become apparent on emerging spikes (Cruz and Valent 2017; Urashima 2010). Once the pathogen damages the rachis, it restricts water and nutrient transport to the developing grain (Prabhu et al. 1992; Torres et al. 2009), grain fill is reduced, and spikes become bleached with shriveled, lightweight kernels (Goulart et al. 2007). An entire field may become diseased in a short time, with $100 \%$ incidence and severity, leading to complete yield loss (Cruz and Valent 2017; Kohli et al. 2011).

${ }^{\dagger}$ Corresponding author: P. A. Paul; paul.661@osu.edu

Funding: This project was supported by Agriculture and Food Research Initiative competitive grant no. 2013-68004-20378 from the United States Department National Institute of Food and Agriculture and The Ohio State University Department of Plant Pathology. Salaries and research support for K. B. Mills, J. D. Salgado, L. V. Madden, and P. A. Paul were provided by state and federal funds to the Ohio Agricultural Research and Development Center.

The author(s) declare no conflict of interest.

Accepted for publication 6 July 2020

() 2021 The American Phytopathological Society
Wheat blast emerged in the state of Paraná, Brazil, in 1985 (Prabhu et al. 1992) and quickly spread to other wheat production regions of South America (Ceresini et al. 2018, 2019). The first major outbreak in Bolivia was reported in 1996, with an estimated yield loss of almost $80 \%$ (Barea and Toledo 1996), then in 2002, Paraguay lost $>70 \%$ of its early-planted wheat crop to blast (Kohli et al. 2011; Martínez et al. 2019), followed in 2007 by the first report of the disease in Argentina (Cabrera and Gutiérrez 2007). Until recently, wheat blast was limited to regions of South America, but in February 2016 an outbreak occurred in Bangladesh (Malaker et al. 2016). The disease now poses a threat to wheat production in other countries in Asia such as China, Pakistan, and India (Cruz and Valent 2017), and there are growing concerns about its potential to affect the global wheat market if it continues to spread. In the United States, blast may threaten wheat production through the incursion of MoT isolates from South America or infections caused by native isolates of the Lolium pathotype of the Magnaporthe oryzae (MoL) (Mills et al. 2020). The possibility of the latter occurring is supported by the fact that a blast-affected spike was observed in Kentucky in 2011, and subsequent characterization of the causal agent showed that it was more closely related to local MoL than to South American MoT isolates of the pathogen (Farman et al. 2017).

Studies have been conducted to evaluate management strategies for wheat blast based largely on fungicide application and cultivar resistance (Cruz et al. 2010, 2012; Rios et al. 2016), but research into the epidemiology of this disease is still in its infancy (Cruz et al. 2016; Gongora-Canul et al. 2020; Mills et al. 2020). For instance, there is an incomplete understanding of how the disease develops and spreads in time and space through naturally infected fields. Growers and researchers have described, in some instances, a sudden, uniform, and synchronized bleaching of spikes across entire fields, without observing prior disease symptoms (Cruz et al. 2015). In Bangladesh, blast was portrayed as emerging ex nihilo, then quickly spreading across five districts in $<2$ weeks (Sadat and Choi 2017). However, despite suggestions of "spontaneous" bleaching, there is increasing evidence, based on the presence of the pathogen on basal leaves, that the disease may be spreading from local infield inoculum sources (Cruz et al. 2015; Gongora-Canul et al 
2020; Rios et al. 2013). Basal leaf lesions have been observed to sporulate during spike emergence, but it is unknown whether these are important sources of inoculum for the spike blast phase of the disease or whether infected crop residue plays a major role in disease development (Cruz et al. 2015).

Studies of spatial and temporal progress are important for elucidating disease dynamics under field conditions and are invaluable for developing management guidelines such as fungicide application, tillage, and crop rotation. Disease progress in space and time is a function of interactions between the host plant, the pathogen, and the environment (Madden et al. 2007). This process can be modeled under natural field conditions to address questions such as whether wheat blast is a monocyclic or a polycyclic disease (GongoraCanul et al. 2020) and whether in-field crop residue or neighboring grassy weeds act as primary sources of inoculum for disease development. For instance, a monocyclic epidemic may be better described by the monomolecular model, whereas the exponential, logistic, or Gompertz models may be more appropriate for describing the temporal progress of a polycyclic epidemic (Madden et al. 2007). The best-fit population growth model would provide insights into the relative importance of primary and secondary inoculum and infection for disease development. Models can also be used to compare epidemics between locations, growing seasons, cultivars, and management practices (Madden et al. 2007; Waggoner 1986), all of which are important for developing and implementing strategies for minimizing grain yield and quality losses.

To address key knowledge gaps in the epidemiology of wheat blast, the current investigation was conducted to monitor, model, and compare naturally occurring wheat spike blast epidemics in Bolivia. The specific objectives were to quantify the temporal progress of spike blast under different growing conditions, estimate time to specific spike blast severity thresholds as influenced by local conditions, and determine the effect of leaf blast severity on spike blast epidemics. To accomplish these objectives, field plots were established in three distinct humidity zones in the Santa Cruz de la Sierra region of the country where the disease is endemic, and incidence and severity data were collected at regular intervals between disease onset and crop senescence. Models were then fitted to quantify and compare the temporal rate of change in spike blast intensity between the locations, and parameters from the best-fit models were used to estimate the time it took for blast severity to reach predetermined thresholds as influenced by field location and leaf blast severity based on time-toevent (survival) analysis.

\section{Materials and Methods}

Field plot establishment and management. Three experiments were conducted in commercial wheat fields in the agricultural region north of Santa Cruz de la Sierra, Bolivia, during the fall and winter of 2015. Plots were established at Okinawa $1\left(\mathrm{OK} 1 ; 17^{\circ} 14.55^{\prime} \mathrm{S}\right.$, $\left.62^{\circ} 53.35^{\prime} \mathrm{W}\right)$; Okinawa $2\left(\mathrm{OK} 2 ; 17^{\circ} 20.41^{\prime} \mathrm{S}, 62^{\circ} 52.60^{\prime} \mathrm{W}\right)$, and Cuatro Cañadas $\left(\mathrm{CC} ; 17^{\circ} 26.48^{\prime} \mathrm{S}, 62^{\circ} 35.91^{\prime} \mathrm{W}\right)$. The Okinawa locations were selected for this study because they had high levels of wheat blast in 2013, an abnormally warm growing season (C. D. Cruz, personal communication). Cuatro Cañadas was chosen as the third location because it was reported to be in a dryer, less humid region compared with the Okinawa locations (Barea and Aguanta 2012). The year this study was conducted was predicted to experience a very strong El Niño-Southern Oscillation event, which suggested that conditions would have been highly conducive for wheat blast (Kohli et al. 2011). According to Kohli et al. (2011), an El Niño year in parts of South America where wheat blast is endemic is characterized by frequent rainfall and temperatures between 18 and $25^{\circ} \mathrm{C}$ during anthesis, followed by warm, humid days. The anticipated weather event did occur, and high levels of wheat blast developed throughout the Santa Cruz de la Sierra region.

To maximize the chance of natural infection, fields were planted at earlier dates than those typically chosen in commercial production fields. Plots were planted on 15 April at OK1, 20 April at OK2, and 8 May at CC. A highly susceptible wheat cultivar, Atlax (CAICO, Santa Cruz de la Sierra, Bolivia), was planted at a seeding rate of $80 \mathrm{seeds} / \mathrm{m}$ and a row spacing of $20 \mathrm{~cm}$. Six $27-\times 27-\mathrm{m}$ plots were planted at each location, with a 2 -m border of sorghum separating adjacent plots. At both $\mathrm{OK} 1$ and $\mathrm{OK} 2$, a single row of plots was planted from east to west, whereas at $\mathrm{CC}$, two rows, each with three plots, were planted. Plots were managed by collaborators from the Asociación de Productores de Oleaginosas y Trigo (ANAPO) Agriculture Cooperative in accordance with recommended agronomic practices for wheat cultivation in Bolivia (ANAPO 2015). Temperature and RH were recorded hourly with sensors and weatherproof data loggers deployed at spike height (approximately $1 \mathrm{~m}$ above the soil surface) in the center of one plot at each location. Rainfall data were recorded on weather stations located approximately 100, 300 , and 3,000 $\mathrm{m}$ from the plots at OK1, CC, and OK2, respectively.

Disease quantification. A two-stage cluster sampling approach was used to quantify wheat blast intensity. At each location, each plot was marked to create a $10 \times 10$ grid, and blast assessments were made at each of the 100 intersection nodes (sampling sites) of the grid. The distance between adjacent nodes was approximately $2.55 \mathrm{~m}$. Spike emergence was asynchronous and occurred over the course of about 10 days, with some secondary tillers heading as grain fill occurred on primary tillers. To minimize possible effects of such a wide heading window, spikes in the primary group of tillers were rated for blast. At each sampling site (i.e., node of the field lattice), blast severity (SEV) was estimated on individual spikes ( $n=5$ to 30 ; a cluster) as the proportion of spikelets with visual symptoms. Incidence (INC) was quantified as the proportion of diseased spikes at each node (number of spikes with blast symptoms divided by the total number of spikes in the sample). We estimated the severity of leaf blast (LEAF; based on symptom characteristics) at each node by examining the flag leaves of four sets of five primary tillers and estimating the mean proportion of leaf area diseased. LEAF was also rated at each internode (approximately halfway between adjacent nodes) at OK1 and OK2, for an additional 81 leaf severity ratings per plot.

Spike severity ratings began at approximately full head emergence (Feekes growth stage 10.5; Large 1954) at each location (9 June at OK1, 18 June at OK2, 10 July at CC) and repeated every 3 to 4 days until primary tillers reached the soft dough growth stage, Feekes 11.2 (29 June at OK1, 13 July at OK2, 7 August at CC). A final disease assessment was made at the soft dough stage because this was the time after which it became difficult to differentiate between diseased and naturally senescent spikes. The length of time from spike emergence to senescence, and consequently the number of assessments, varied between locations. LEAF ratings were initiated before Feekes 10.5 at $\mathrm{OK} 2$ and $\mathrm{CC}$, when most of the field was at Feekes 9. At OK1, the first set of LEAF ratings were made when the majority of the field was at Feekes 10.5.1. Because of weather and time constraints, two of the six plots were not rated at CC, and plots at OK2 were not rated between June 28 and July 9. Additionally, the final disease assessment at OK2 was made on only two of the six plots. Consequently, approximately 3,600 assessments were made at CC (four plots $\times$ sampling 100 sites $\times$ nine assessment per sampling site), compared with 3,000 at OK1 (six plots $\times 100$ sites $\times$ five assessments per site) and 3,100 at OK2 (two to six plots $\times 100$ sites $\times$ one to six assessments per site).

Data analysis. Temporal development of spike blast. For spike blast incidence (INC) and severity (SEV), means at each assessment time, averaged across sampling nodes and plots, were estimated and used to model the temporal dynamics of spike blast. Because a few of the early assessments were made before heading was widespread, nodes with $<15$ spikes were not included in the final datasets because of the low precision of means with such small numbers of observations (Madden et al. 2007). Separate monomolecular, exponential, logistic, and Gompertz population growth models (Madden et al. 2007), in their nonlinear forms, were fitted to the means of the distributions of INC and SEV at each assessment time using the MODEL procedures of SAS. Diagnostic plots generated through the plots option in PROC MODEL were used along with fit statistics such as mean squared error (MSE) and $R^{2}$ as measures of model performance. Before the final model to estimate parameters and compare epidemics was selected, a series of preliminary model-fitting steps 
were run to check and correct for heteroscedasticity and serial correlation of residuals (see Madden and Hughes 1995 for details). White (1980) and the modified Breusch-Pagan (Breusch and Pagan 1979) tests of heteroscedasticity, and the Durbin-Watson (Durbin and Watson 1950) and Godfrey Lagrange multiplier (Godfrey 1978a, b) tests for residual autocorrelation were run through the fit statement in PROC MODEL to test the null hypotheses of homoscedasticity and uncorrelated residuals, respectively. For situations in which the null hypothesis of homoscedasticity was rejected (Table 1), models were refitted using weights as recommended by Madden and Hughes (1995) and Madden et al. (2007) to correct for heteroscedasticity. Weights was defined as:

$$
W_{i}=\frac{1}{I N C(1-I N C)}
$$

for incidence and

$$
W_{s}=\frac{1}{S E V(1-S E V)}
$$

for severity.

Because disease progress was quantified as a time series, incidence and severity values at a certain time were assumed to be correlated with prior values; that is, recurring assessments were not biologically independent from each other (Madden and Hughes 1995). This may translate into correlation of residuals. Lack of independence and, consequently, high autocorrelation of residuals may lead to artificially low standard errors of parameter estimates, which in turn may lead to erroneous conclusions when we are comparing epidemics (Madden and Hughes 1995), a primary focus of the current investigation. To correct for autocorrelation, models for which the null hypothesis of no serial correlation was rejected (Table 1) were refitted with a first-order autoregressive [AR(1)] error term via the $\%$ AR macro in PROC MODEL. Autocorrelation and partial autocorrelation function plots (plots of the correlation coefficients and partial correlation coefficients, respectively, versus time lags) were used as a guide for defining the number of AR terms to include in the model

Based on the statistics in Table 2, residual and raw data plots, and statistics from linear regression analyses of relationships between predicted and observed blast intensity, the logistic model was chosen as the most appropriate for describing the dynamics of wheat spike blast at all locations. Although the exponential model fit the data just as well as the logistic model in most cases (Table 2), the latter was chosen over the former because it is more biologically meaningful. Unlike the logistic model, the exponential model does not have term for healthy individuals or tissues, meaning it assumes that the number of healthy individuals is at a maximum throughout an epidemic; that is, the rate of disease progress is not slowed down by the depletion of healthy individuals or tissues (Madden et al. 2007). This assumption is unrealistic for making any predictions when disease is not low, particularly in our case, where a finite number of spikes of a fixed size were rated. The nonlinear forms of this model can be written as:

$$
y=\frac{1}{1+\left(\frac{1-y_{0}}{y_{0}}\right) e^{\left(-r_{L} t\right)}},
$$

where $y$ is disease intensity (INC or SEV; as a proportion), $r_{L}$ is the rate parameter (per day), $t$ is time in days after Feekes 10.5, and $y_{0}$ is disease intensity at the start of the epidemic. Estimated model parameters and predicted mean blast intensity, averaged across sample nodes and plots, were used along with their standard errors to compare epidemics between the three locations by using Welch's independent-sample $t$ tests (Derrick et al. 2016; Madden et al. 2007; Welch 1947). This is a modification of the Student $t$ test that

Table 1. Statistics and levels of significance for tests of serial correlation and heteroscedasticity from the fit of population growth models to wheat blast incidence

\begin{tabular}{|c|c|c|c|c|c|c|c|c|c|c|c|}
\hline \multirow[b]{3}{*}{ Location } & \multirow[b]{3}{*}{ Response } & \multirow[b]{3}{*}{ Model } & \multicolumn{5}{|c|}{ Serial correlation $^{a}$} & \multicolumn{4}{|c|}{ Heteroscedasticity ${ }^{\mathbf{b}}$} \\
\hline & & & \multicolumn{3}{|c|}{ Durbin-Watson } & \multicolumn{2}{|c|}{ Godfrey } & \multicolumn{2}{|c|}{ White } & \multicolumn{2}{|c|}{ Breusch-Pagan } \\
\hline & & & $d$ & $P<\mathrm{DW}$ & $P>D W$ & LM & $P$ & $\mathbf{W}$ & $P$ & BP & $P$ \\
\hline \multirow[t]{8}{*}{$\mathrm{CC}$} & Incidence & Exponential & 1.34 & 0.023 & 0.977 & 5.38 & 0.020 & 8.26 & 0.142 & 1.03 & 0.311 \\
\hline & & Monomolecular & 0.72 & $<0.001$ & 0.999 & 15.62 & $<0.001$ & 20.85 & 0.001 & 2.34 & 0.127 \\
\hline & & Logistic & 2.02 & 0.482 & 0.518 & 0.01 & 0.924 & 7.15 & 0.210 & 0.27 & 0.602 \\
\hline & & Gompertz & 1.60 & 0.115 & 0.885 & 1.15 & 0.284 & 3.71 & 0.593 & 0.53 & 0.465 \\
\hline & Severity & Exponential & 2.03 & 0.516 & 0.484 & 0.03 & 0.865 & 13.77 & 0.017 & 4.84 & 0.028 \\
\hline & & Monomolecular & 0.72 & $<0.001$ & 0.998 & 18.46 & $<0.001$ & 26.10 & $<0.001$ & 12.26 & $<0.001$ \\
\hline & & Logistic & 1.93 & 0.403 & 0.597 & 0.04 & 0.843 & 12.43 & 0.029 & 4.62 & 0.032 \\
\hline & & Gompertz & 1.61 & 0.126 & 0.874 & 1.23 & 0.267 & 7.35 & 0.025 & 3.43 & 0.064 \\
\hline \multirow[t]{8}{*}{ OK1 } & Incidence & Exponential & 1.09 & 0.002 & 0.999 & 7.10 & 0.008 & 18.80 & 0.002 & 6.27 & 0.012 \\
\hline & & Monomolecular & 2.05 & 0.504 & 0.496 & 0.03 & 0.857 & 3.99 & 0.551 & 1.40 & 0.237 \\
\hline & & Logistic & 1.44 & 0.037 & 0.963 & 2.36 & 0.124 & 7.34 & 0.197 & 0.01 & 0.913 \\
\hline & & Gompertz & 1.63 & 0.120 & 0.880 & 1.04 & 0.308 & 5.58 & 0.350 & 0.80 & 0.373 \\
\hline & Severity & Exponential & 0.87 & $<0.001$ & 0.999 & 11.53 & $<0.001$ & 15.53 & 0.008 & 12.84 & 0.003 \\
\hline & & Monomolecular & 1.40 & 0.023 & 0.977 & 3.69 & 0.055 & 7.26 & 0.123 & 2.26 & 0.133 \\
\hline & & Logistic & 0.84 & $<0.001$ & 0.999 & 11.36 & $<0.001$ & 16.53 & 0.006 & 14.19 & $<0.001$ \\
\hline & & Gompertz & 0.84 & $<0.001$ & 0.999 & 11.62 & 0.001 & 13.34 & 0.020 & 11.67 & 0.001 \\
\hline \multirow[t]{8}{*}{$\mathrm{OK} 2$} & Incidence & Exponential & 2.49 & 0.917 & 0.084 & 3.96 & 0.047 & 30.48 & $<0.001$ & 24.35 & $<0.001$ \\
\hline & & Monomolecular & 1.78 & 0.262 & 0.738 & 0.17 & 0.679 & 29.87 & $<0.001$ & 19.22 & $<0.001$ \\
\hline & & Logistic & 2.35 & 0.847 & 0.153 & 2.23 & 0.136 & 11.74 & 0.039 & 0.14 & 0.710 \\
\hline & & Gompertz & 1.67 & 0.216 & 0.785 & 4.19 & 0.041 & 12.21 & 0.002 & 0.53 & 0.465 \\
\hline & Severity & Exponential & 1.90 & 0.447 & 0.553 & 0.02 & 0.883 & 15.04 & 0.005 & 7.78 & 0.005 \\
\hline & & Monomolecular & 1.95 & 0.422 & 0.578 & 0.02 & 0.883 & 29.69 & $<0.001$ & 12.97 & $<0.001$ \\
\hline & & Logistic & 1.88 & 0.436 & 0.564 & 0.04 & 0.844 & 14.76 & 0.005 & 7.67 & 0.006 \\
\hline & & Gompertz & 2.51 & 0.915 & 0.085 & 3.86 & 0.049 & 23.24 & $<0.001$ & 18.00 & $<0.001$ \\
\hline
\end{tabular}
(mean proportion of diseased spikes) and severity (mean percentage of diseased spikelets per spike) data collected from separate fields in Cuatro Cañadas (CC), Okinawa 1 (OK1), and Okinawa 2 (OK2), near Santa Cruz de la Sierra, Bolivia in 2015 
is robust to unequal variability between estimates from the three locations that probably resulted from differences in growing conditions and sample sizes. Because crop growth and development varied between locations, predicted mean incidence and severity at 21 days after full head emergence were compared instead of final incidence and severity at any one calendar date.

Time-to-event analysis. For some pathosystems, there are certain critical levels of disease at or above which yield and quality losses may occur (Madden et al. 2007) and at which management or grain marketing decisions are made. One approach for using models of disease dynamics to help guide decision making is to estimate the time it takes for disease intensity to reach predetermined thresholds and compare the results between experimental factors, locations, or growing seasons (Madden et al. 2007). Separate logistic models were fitted to mean spike blast data from each sample node, and the resulting parameters were used to estimate the time (in days) it took for blast severity to reach thresholds of 10,15 , and $20 \%$ at each node at each location by solving Equation 2 for time, $t$. The equation can be written as:

$$
t_{s}=\frac{\ln \left(\frac{1-y_{s}}{y_{s}}\right)-\ln \left(\frac{1-y_{0}}{y_{0}}\right)}{-r_{L}},
$$

where $t_{S}$ is time in days from Feekes 10.5 to 10,15 , or $20 \%$ severity $\left(t_{10}, t_{15}\right.$, or $t_{20}$, respectively), $y_{S}$ is the specific severity threshold $\left(y_{10}\right.$, $y_{15}$, or $\left.y_{20}\right)$, and $y_{0}$ and $r_{L}$ are parameters for the logistic models as defined above. These thresholds were loosely based on the work of Rios et al. (2016), which showed that 10, 15, and $20 \%$ spike blast severity at 14 days after inoculation (anthesis) were associated with grain yield reductions of approximately 35,52 , and $88 \%$, respectively.

The $t_{S}$ data were right censored because the disease levels of interest were not always reached by the end of the observation period. To account for this situation, a survival analysis was performed for the $t_{S}$ data (Nesi et al. 2013; Ojiambo and Scherm 2005; Scherm and Ojiambo 2004). Using each node as a separate observation, we estimated the probability of severity not reaching ("surviving") $y_{10}, y_{15}$, or $y_{20}$ by 21 data after Feekes 10.5 for the population of nodes at each location. Based on the estimated $t_{S}$ values, rounded to the nearest day, each observation was assigned a code of 1 if $y_{S}$ was reached by day 21 after heading (considered here as the event of interest) and 0 otherwise (considered as censored). In other words, observations with $t_{S}$ $>21$ were considered censored at 21 days after heading (Table 3). Time-to-event (also known as survival) analysis was then performed with the LIFETEST procedure of SAS, through which the KaplanMeier method (Kaplan and Meier 1958) was used to estimate survivor functions and the life table method was used to construct survival curves for each $y_{S}$ at each location (Allison 2010). Survival curves are plots of the probability of "surviving" a specific disease threshold for $\geq 21$ days after heading. To determine the effect of location on time to 10,15 , or $20 \%$ spike blast severity, the null hypothesis of no difference in survival curves (survivor functions) between locations was tested with the log-rank test in PROC LIFETEST (Allison 2010; Bland and Altman 2004; Goel et al. 2010).

Leaf blast effect on spike blast survivor function. The association between leaf and spike blast is still largely unknown, but the fact that lesions on leaves are capable of producing copious amounts of spores

Table 2. Estimated parameters and corresponding statistics from nonlinear regression fit of population growth models to spike blast incidence (mean proportion of diseased spikes) and severity (mean proportion of diseased spikelets per spike) data collected from Cuatro Cañadas (CC), Okinawa 1 (OK1), and Okinawa 2 (OK2), near Santa Cruz de la Sierra, Bolivia in 2015

\begin{tabular}{|c|c|c|c|c|c|c|c|}
\hline \multirow[b]{2}{*}{ Response } & \multirow[b]{2}{*}{ Location } & \multicolumn{6}{|c|}{ Parameters and statistics $^{a}$} \\
\hline & & $y_{0}$ & $\operatorname{se}\left(y_{0}\right)$ & $r$. & $\operatorname{se}\left(r_{\bullet}\right)$ & MSE & $R^{2}$ \\
\hline \multicolumn{8}{|c|}{ Exponential } \\
\hline \multirow[t]{3}{*}{ Incidence } & $\mathrm{CC}$ & $5.20 \mathrm{E}-02$ & $1.80 \mathrm{E}-02$ & 0.102 & 0.013 & 0.009 & 0.93 \\
\hline & OK1 & $1.90 \mathrm{E}-01$ & $3.20 \mathrm{E}-02$ & 0.079 & 0.008 & 0.075 & 0.88 \\
\hline & $\mathrm{OK} 2$ & $1.20 \mathrm{E}-02$ & $2.40 \mathrm{E}-03$ & 0.191 & 0.008 & 0.017 & 0.99 \\
\hline \multirow[t]{3}{*}{ Severity } & $\mathrm{CC}$ & $1.60 \mathrm{E}-03$ & $5.10 \mathrm{E}-04$ & 0.213 & 0.012 & 0.025 & 0.95 \\
\hline & OK1 & $1.50 \mathrm{E}-02$ & $4.70 \mathrm{E}-03$ & 0.190 & 0.016 & 0.052 & 0.88 \\
\hline & OK2 & $8.40 \mathrm{E}-05$ & $6.70 \mathrm{E}-05$ & 0.349 & 0.031 & 0.020 & 0.94 \\
\hline \multicolumn{8}{|c|}{ Monomolecular } \\
\hline \multirow[t]{3}{*}{ Incidence } & $\mathrm{CC}$ & $-5.93 \mathrm{E}-01$ & $2.44 \mathrm{E}-01$ & 0.030 & 0.005 & 0.380 & 0.72 \\
\hline & OK1 & $-1.21 \mathrm{E}-01$ & 4.84E-02 & 0.080 & 0.006 & 0.011 & 0.87 \\
\hline & OK2 & $-2.44 \mathrm{E}-01$ & 8.87E-02 & 0.105 & 0.016 & 2.556 & 0.88 \\
\hline \multirow[t]{3}{*}{ Severity } & $\mathrm{CC}$ & $-5.35 \mathrm{E}-01$ & $1.98 \mathrm{E}-01$ & 0.020 & 0.003 & 0.120 & 0.76 \\
\hline & OK1 & $-2.59 \mathrm{E}-01$ & 7.30E-02 & 0.047 & 0.007 & 0.010 & 0.78 \\
\hline & OK2 & $-1.06 \mathrm{E}-01$ & $3.94 \mathrm{E}-02$ & 0.023 & 0.004 & 0.016 & 0.63 \\
\hline \multicolumn{8}{|c|}{ Logistic } \\
\hline \multirow[t]{3}{*}{ Incidence } & $\mathrm{CC}$ & $1.90 \mathrm{E}-03$ & $8.20 \mathrm{E}-04$ & 0.307 & 0.021 & 0.003 & 0.98 \\
\hline & OK1 & $7.55 \mathrm{E}-02$ & $2.00 \mathrm{E}-02$ & 0.220 & 0.025 & 0.011 & 0.87 \\
\hline & OK2 & $5.50 \mathrm{E}-04$ & $3.00 \mathrm{E}-04$ & 0.540 & 0.047 & 0.026 & 0.99 \\
\hline \multirow[t]{3}{*}{ Severity } & $\mathrm{CC}$ & $1.90 \mathrm{E}-04$ & $6.70 \mathrm{E}-05$ & 0.331 & 0.014 & 0.011 & 0.98 \\
\hline & OK1 & $5.90 \mathrm{E}-03$ & $1.90 \mathrm{E}-03$ & 0.285 & 0.018 & 0.041 & 0.90 \\
\hline & OK2 & $3.90 \mathrm{E}-08$ & $8.60 \mathrm{E}-08$ & 0.695 & 0.091 & 0.021 & 0.93 \\
\hline \multicolumn{8}{|c|}{ Gompertz } \\
\hline \multirow[t]{3}{*}{ Incidence } & $\mathrm{CC}$ & $8.80 \mathrm{E}-25$ & $1.44 \mathrm{E}-23$ & 0.220 & 0.015 & 0.003 & 0.98 \\
\hline & OK1 & $2.48 \mathrm{E}-02$ & $1.56 \mathrm{E}-02$ & 0.153 & 0.015 & 0.010 & 0.89 \\
\hline & OK2 & 2.63E-45 & $1.28 \mathrm{E}-43$ & 0.348 & 0.055 & 0.002 & 0.99 \\
\hline \multirow[t]{3}{*}{ Severity } & $\mathrm{CC}$ & $2.49 \mathrm{E}-43$ & $5.86 \mathrm{E}-42$ & 0.194 & 0.010 & 0.013 & 0.97 \\
\hline & OK1 & $2.30 \mathrm{E}-05$ & $3.20 \mathrm{E}-05$ & 0.151 & 0.009 & 0.034 & 0.92 \\
\hline & $\mathrm{OK} 2$ & $1.90 \mathrm{E}-05$ & $6.50 \mathrm{E}-05$ & 0.113 & 0.016 & 0.065 & 0.80 \\
\hline
\end{tabular}

${ }^{\mathrm{a}} \mathrm{MSE}=$ estimated mean squared error, the average squared difference between estimated and actual incidence or severity values; $r_{\boldsymbol{\bullet}}=$ rate parameter for the exponential $\left(r_{\mathrm{E}}\right)$, monomolecular $\left(r_{\mathrm{M}}\right)$, logistic $\left(r_{\mathrm{L}}\right)$, and Gompertz $\left(r_{\mathrm{G}}\right)$ models; $R^{2}=$ percentage variability in blast intensity explained by the estimated model over the variability explained by a mean model; $\operatorname{se}\left(r_{\bullet}\right)=$ standard error of $r_{\boldsymbol{\bullet}} ; \operatorname{se}\left(y_{0}\right)=$ standard error of $y_{0} ; y_{0}=$ initial level of incidence or severity. 
has led some researchers to hypothesize that leaf blast is a potential source of inoculum for the development of spike blast (Cruz et al. 2015; Gongora-Canul et al. 2020). Here we expanded the time-toevent analysis to determine whether leaf blast severity at approximately 21 days after Feekes 10.5 (20 days after at OK1, 21 days after at $\mathrm{CC}$, and 23 days after at $\mathrm{OK} 2$ ) affected the probability of spike blast reaching 10,15 , or $20 \%$ severity by 21 days after heading. Repeating the analyses described previously, we included LEAF as a categorical fixed effect with three levels (LEAF $<25 \%$, LEAF 25 to $<50 \%$, and LEAF $\geq 50 \%$ ), estimated and plotted survivor functions for each location $\times$ LEAF category combination, and tested the null hypothesis of no difference in survivor functions between pairs of location $\times$ LEAF combinations. Then, based on the results, we used the test statement in PROC LIFETEST to estimate the direction and significance of the association between LEAF as a continuous covariate and time-to-event (SEV reaching 10, 15, or $20 \%$ by 21 days after heading) at each location.

Quantifying the magnitude of location and leaf blast severity effects. The analyses described in the previous two paragraphs provide estimates of the significance of location and leaf blast effects of spike blast survivor function, but for reasons outlined in Allison (2010), they are not the best approaches for quantifying the magnitude of these effects. In addition, none of the commonly used survival (lifetime) distributions, necessary for valid implementation of parametric accelerated failure time regression analyses in PROC LIFEREG, appeared to be appropriate for our dataset. We therefore fitted semiparametric Cox regression models (Allison 2010) to the survival data, with location and LEAF as categorical and continuous covariates, respectively. However, because the proportional hazards assumption was not met (i.e., the "failure rate" depended on time or a time-varying covariate), instead of using the common Cox proportional hazards modeling approach, we fitted nonproportional hazard models by using the PHREG procedure in SAS, with time-dependent covariates included in the models. We modeled the effect of location (recoded as 1 for CC, 2 for OK1, and 3 for OK2) on time to 10, 15, and $20 \%\left(y_{10}, y_{15}\right.$, and $\left.y_{20}\right) \mathrm{SEV}$, with location $\times$ time $\left(t_{\mathrm{s}}\right)$ interaction terms included in the models as the time-dependent covariates. Class, contrast, and estimate statements in PROC PHREG were then used for hypothesis testing and to compare locations based on hazard ratios.

Similarly, the effect of LEAF was modeled in PROC PHREG, with LEAF $\times t_{\mathrm{s}}$ interaction terms included in the models as timedependent covariates to account for the fact that proportional hazard assumption was violated. Rates of increase in the likelihood of SEV reaching the specific thresholds (hazard ratio) for every 5\% increase in LEAF were then estimated from the model parameters along with their $95 \%$ confidence intervals. The effect of LEAF was quantified only at OK1, because results from the LIFETEST procedure indicated that leaf blast severity did not affect the survivor functions at $\mathrm{CC}$ and affected the function at $\mathrm{OK} 2$ only when the probability of SEV reaching $15 \%$ was estimated.

\section{Results}

Growing conditions and crop and wheat blast development. Growing conditions and crop development varied between locations. Mean temperature and $\mathrm{RH}$ were 20 to $21^{\circ} \mathrm{C}$ and $89 \%$, respectively, at $\mathrm{OK} 1$ and $\mathrm{OK} 2$, compared with $22.4^{\circ} \mathrm{C}$ and $82 \% \mathrm{RH}$ at CC. At CC, a single major rainfall event of $70 \mathrm{~mm}$ occurred during the first week of heading (Fig. 1A), whereas at OK1 it rained on 4 of the 7 days, for a total of $64 \mathrm{~mm}$ (Fig. 1B). Barring a single rainfall event of $1.60 \mathrm{~mm}$, it was rain-free during the first week and a half after initial heading at OK2, after which it rained on 6 of the next 8 days, for a total of $126 \mathrm{~mm}$ (Fig. 1C). Spike emergence (Feekes 10.5) was earliest and most synchronized at $\mathrm{OK} 1$ and latest and most asynchronized at CC. The first set of fully emerged spikes were observed at 56 days after planting (DAP) at OK1, 59 DAP at OK2, and 63 DAP at CC. At approximately 60 DAP, $80 \%$ (481) of the 600 sampling sites (nodes on the grid) at OK1 had 10 to 20 tillers at the Feekes 10.5 growth stage, $80 \%$ of the nodes at OK2 had fewer than six tillers at Feekes 10.5, and 94\% (377) of the 400 nodes at CC had no tillers at Feekes 10.5. At $70 \mathrm{DAP}, \geq 15$ spikes were rated at $68 \%$ of the nodes at $\mathrm{OK} 1,37 \%$ at $\mathrm{OK} 2$, and $9 \%$ at $\mathrm{CC}$.

The first set of spike blast symptoms were observed shortly after spikes emerged at all locations, but initial INC (Fig. 2A, C, and E) and SEV (Fig. 2B, D, and F) were low during the first week and varied between the three locations. For instance, at 6 to 7 days after Feekes 10.5, 77, 47, and $11 \%$ of the nodes were blast free at CC, OK2, and OK1, respectively. The distribution of mean blast intensity also varied between assessment times and locations. At approximately 3 weeks after Feekes 10.5, mean SEV was 57\% at OK1, $28 \%$ at $\mathrm{OK} 2$, and $18 \%$ at CC, with $50 \%$ of the node (sampling site) means between 43 and $71 \%$ (an interquartile range [IQR] of 28\%), between 9 and $40 \%(\mathrm{IQR}=29 \%)$, and between 12 and $24(\mathrm{IQR}=$ $12 \%$ ) at $\mathrm{OK} 1, \mathrm{OK} 2$, and CC, respectively. For INC, the corresponding means and IQRs were 86 and $25 \%, 99$ and $0 \%$, and 53 and $25 \%$. Mean INC and SEV at the time of the last assessment (20, 25, and 28 days after Feekes 10.5 at OK1, OK2, and CC) were 86 and $58 \%$ at $\mathrm{OK} 1,100$ and $74 \%$ at $\mathrm{OK} 2$, and 95 and $71 \%$ at CC.

Mean LEAF at approximately 3 weeks after Feekes 10.5 ranged from 0.6 to $5 \%$ to 98 to $100 \%$, depending on the location (Fig. $2 \mathrm{G}$, $\mathrm{H}$, and I), with an overall mean of $37 \%$ at $\mathrm{OK} 1,28 \%$ at $\mathrm{OK} 2$, and $41 \%$ at CC. Approximately $44 \%$ of the sampling sites at OK1 had

Table 3. Summary of the wheat spike blast severity dataset collected from fields in Cuatro Cañadas (CC), Okinawa 1 (OK1), and Okinawa 2 (OK2) near Santa Cruz de la Sierra, Bolivia in 2015 in terms of the total number of samples collected, and samples classified as events or censored

\begin{tabular}{|c|c|c|c|c|c|c|c|}
\hline \multirow[b]{2}{*}{ Severity $^{\mathbf{a}}$} & \multirow[b]{2}{*}{ Location } & \multirow[b]{2}{*}{ Samples } & \multirow[b]{2}{*}{ Event } & \multirow[b]{2}{*}{ Censored } & \multicolumn{3}{|c|}{ Survival/failure $^{\mathbf{b}}$} \\
\hline & & & & & 7 days & 14 days & 21 days \\
\hline \multirow[t]{4}{*}{$10 \%$} & Cuatro Cañadas & 395 & 318 & 77 & $0.99 / 0.01$ & $0.98 / 0.02$ & $0.27 / 0.73$ \\
\hline & Okinawa 1 & 585 & 585 & 0 & $0.83 / 0.17$ & $0.15 / 0.85$ & $0.00 / 1.00$ \\
\hline & Okinawa 2 & 161 & 28 & 133 & 1.00 .0 .00 & $0.99 / 0.01$ & $0.83 / 0.17$ \\
\hline & Total & 1141 & 931 & 210 & & & \\
\hline \multirow[t]{4}{*}{$15 \%$} & Cuatro Cañadas & 395 & 224 & 171 & $1.00 / 0.00$ & $0.99 / 0.01$ & $0.54 / 0.46$ \\
\hline & Okinawa 1 & 593 & 592 & 1 & $0.93 / 0.07$ & $0.29 / 0.71$ & $0.00 / 1.00$ \\
\hline & Okinawa 2 & 161 & 16 & 145 & $1.00 / 0.00$ & $0.99 / 0.01$ & $0.90 / 0.10$ \\
\hline & Total & 1149 & 832 & 317 & & & \\
\hline \multirow[t]{4}{*}{$20 \%$} & Cuatro Cañadas & 395 & 129 & 266 & $1.00 / 0.00$ & $0.99 / 0.01$ & $0.72 / 0.28$ \\
\hline & Okinawa 1 & 593 & 587 & 6 & $0.94 / 0.06$ & $0.45 / 0.55$ & $0.02 / 0.98$ \\
\hline & Okinawa 2 & 161 & 7 & 154 & $1.00 / 0.00$ & $0.99 / 0.01$ & $0.96 / 0.04$ \\
\hline & Total & 1149 & 723 & 426 & & & \\
\hline
\end{tabular}

${ }^{a}$ Mean spike blast severity (mean proportion of diseased spikelets per spike) at 21 days after full head emergence (Feekes 10.5) at and above which a sample (a set of $\geq 15$ spikes per sample site within a field or location) was classified as an event. Samples with mean severity below the cutoff levels at 21 days after Feekes 10.5 were considered censored for time-to-event analysis.

${ }^{\mathrm{b}}$ Probabilities of surviving (survival) and failing to survive (failure) at 7, 14, and 21 days after Feekes 10.5. In other words, these are the estimated probabilities of not reaching (survival) or reaching (failure) 10,15 , or $20 \%$ severity at 7, 14, and 21 days after Feekes 10.5 . 
mean LEAF $<25 \%, 27 \%$ had means between 25 and 50\% (LEAF 25 to $<50 \%$ ), and $29 \%$ had mean LEAF $>50 \%$. The corresponding percentages of mean LEAF in the three categories were 57, 27, and $16 \%$, respectively, at OK2 and 42,17 , and $41 \%$ at CC.

Temporal development of wheat spike blast. For several model-response combinations, there was evidence of serial correlation of residuals and heteroscedasticity, based on the formal statistical tests (Table 1), even though the residual plots did not always reveal these violations (data not shown). With very few exceptions, the two tests for serial correlation and two for heteroscedasticity agreed with each other. The violations tended to be more frequent and consistent across models and locations for severity than for incidence. Models fitted to data from CC had more problems with heteroscedasticity, particularly for severity, than with autocorrelation. For the monomolecular model fitted to incidence and severity data from $\mathrm{CC}$, the null hypotheses of homoscedasticity and uncorrelated residuals were rejected by at
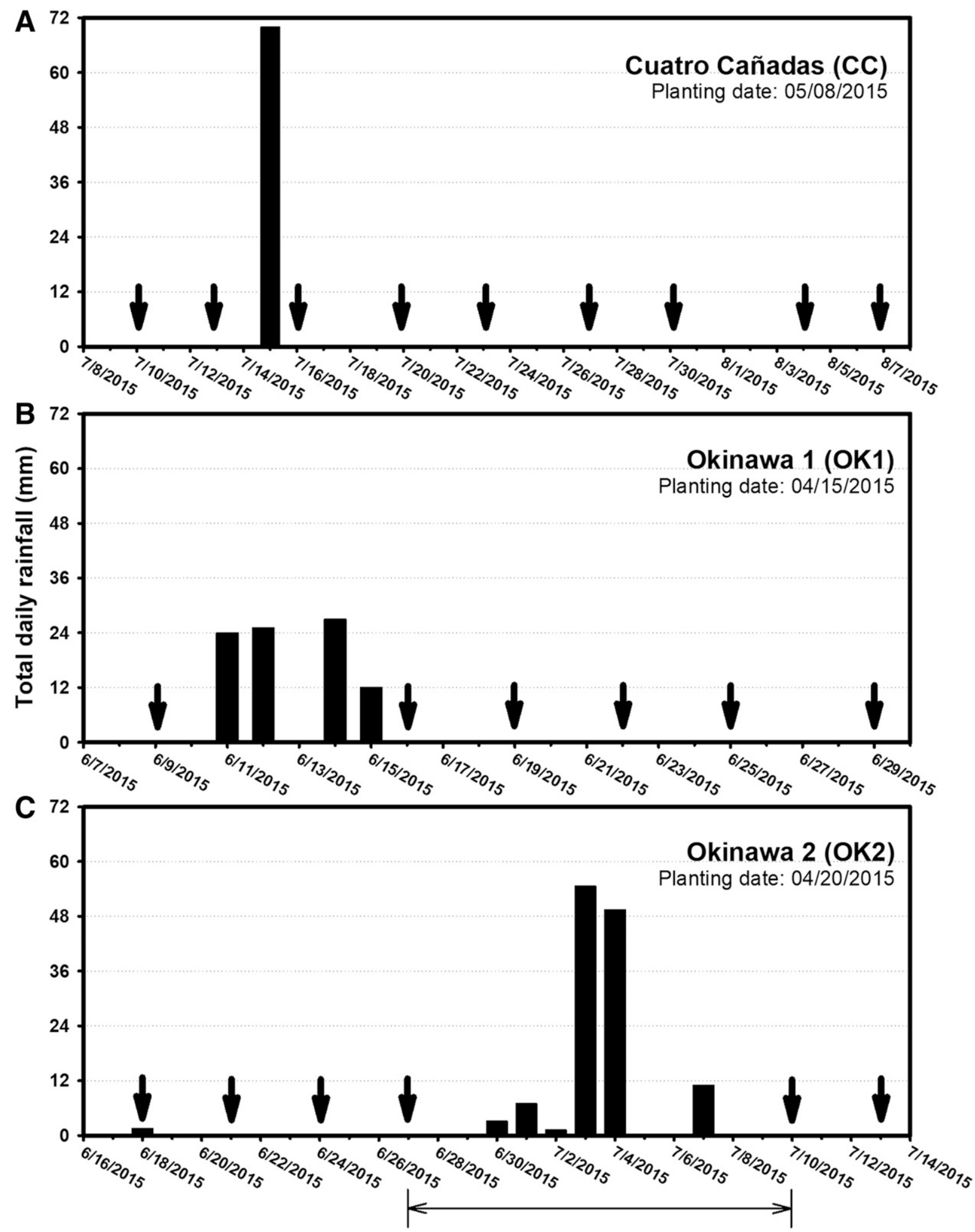

Fig. 1. Total daily rainfall between wheat heading (Feekes growth stage 10.5) and final wheat blast assessment in research plots at A, Cuatro Cañadas $\left(17^{\circ} 26.48^{\prime} \mathrm{S}, 62^{\circ} 35.91^{\prime} \mathrm{W}\right.$ ), B, Okinawa $1\left(17^{\circ} 14.55^{\prime} \mathrm{S}, 62^{\circ} 53.35^{\prime} \mathrm{W}\right)$, and C, Okinawa $2\left(1^{\circ} 20.41^{\prime} \mathrm{S}, 62^{\circ} 52.60^{\prime} \mathrm{W}\right)$ near Santa Cruz de la Sierra, Bolivia. Arrows indicate disease assessment dates, with the first being at Feekes 10.5. The horizontal bar shows the period during which heavy rainfall and flooding prevented access to plots at Okinawa 2. 
least one test $(P<0.05$; Table 1$)$. Similar trends were observed with the exponential models at OK1, with the null hypotheses being rejected for both incidence and severity; with the Gompertz and logistic models, the hypotheses were rejected for severity but not for incidence. At OK2, autocorrelation was less of a problem than heteroscedasticity; the null hypothesis of homoscedasticity was rejected for all model fits by at least one test. Refitting models with weights or with a first-order autoregressive error term corrected for heteroscedasticity and serial correlation of residuals, respectively, in some but not all cases.

The model parameters and statistics in Table 2 are from the fit of models corrected for heteroscedasticity and serial correlation of residuals. Whereas the logistic, exponential, and Gompertz models fit the data reasonably well, the monomolecular model was not a good fit. The mean squared differences in blast intensity between predicted and observed values (MSE) were among the lowest, and $R^{2}$ values were among the highest for the logistic model (Table 2). For instance, for both INC and SEV at CC, the logistic and Gompertz models had the highest and comparable $R^{2}$ values ( 0.97 to 0.98$)$. The same two models had the highest $R^{2}$ for SEV at OK1, but for INC, $R^{2}$ values were comparable ( 0.87 to 0.89 ) between the models. At OK2, the exponential and logistic models had the highest $R^{2}$ for SEV, and this statistic was highest with the exponential model for INC. Patterns of the residual plots were comparable between the models (data not shown).

Based on the fit statistics, the logistic model was chosen as the most appropriate for comparing epidemics between the locations. Estimated initial INC and SEV $\left(y_{0}\right)$ and rate parameters $\left(r_{\mathrm{L}}\right)$ for both measures of spike blast varied between locations. For both INC and SEV, $r_{\mathrm{L}}$ values (Table 2$)$ were significantly greater $(P<$ $0.001)$ at $\mathrm{OK} 2$ than at $\mathrm{OK} 1$ and $\mathrm{CC}$ and significantly higher at $\mathrm{CC}$ than at OK1 for INC but not SEV. Opposite trends were observed for $y_{0}$, with the estimates being significantly higher at OK1 than at $\mathrm{CC}$ and OK2 and greater at CC than at OK2 for SEV but not for INC. Estimated predicted INC at 21 days after Feekes 10.5 was significantly greater at OK1 (89\%) and OK2 (98\%) than at CC (55\%), whereas for SEV the estimated predicted value at 21 days after full
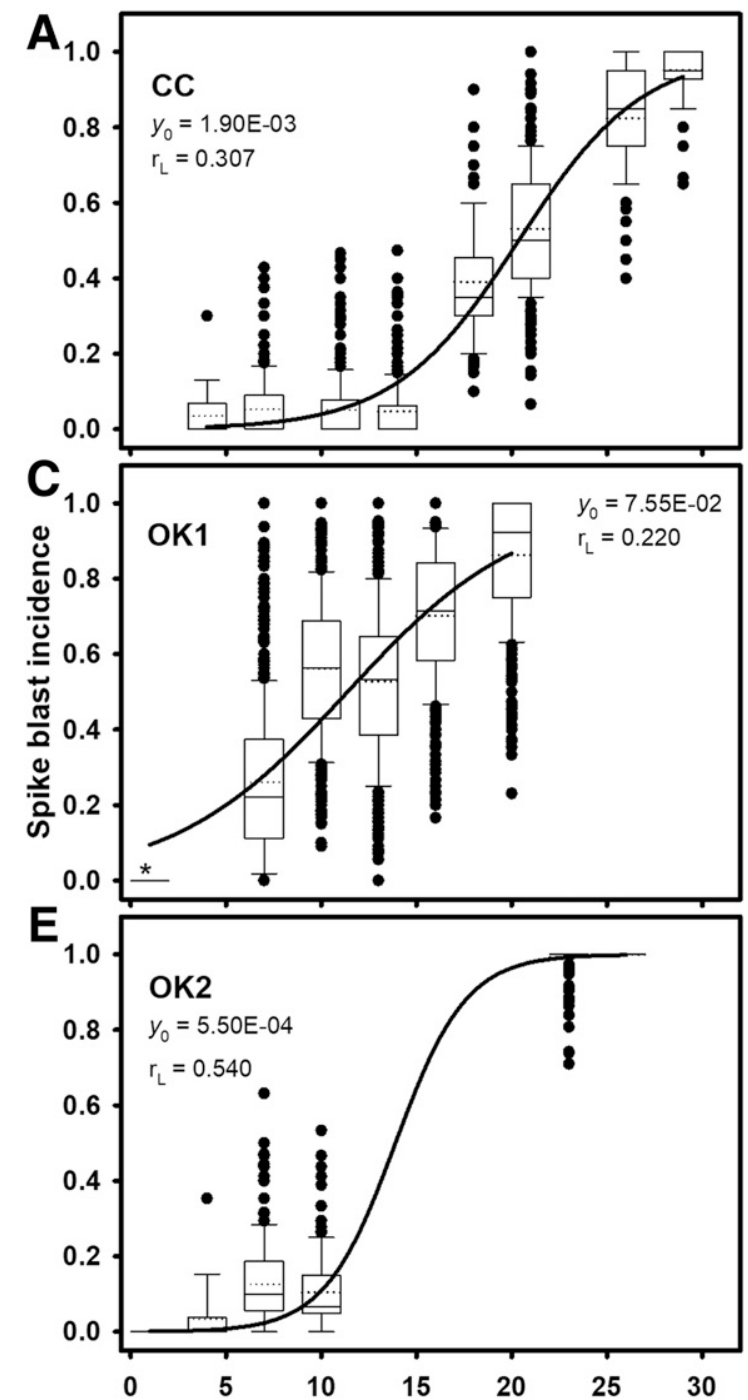
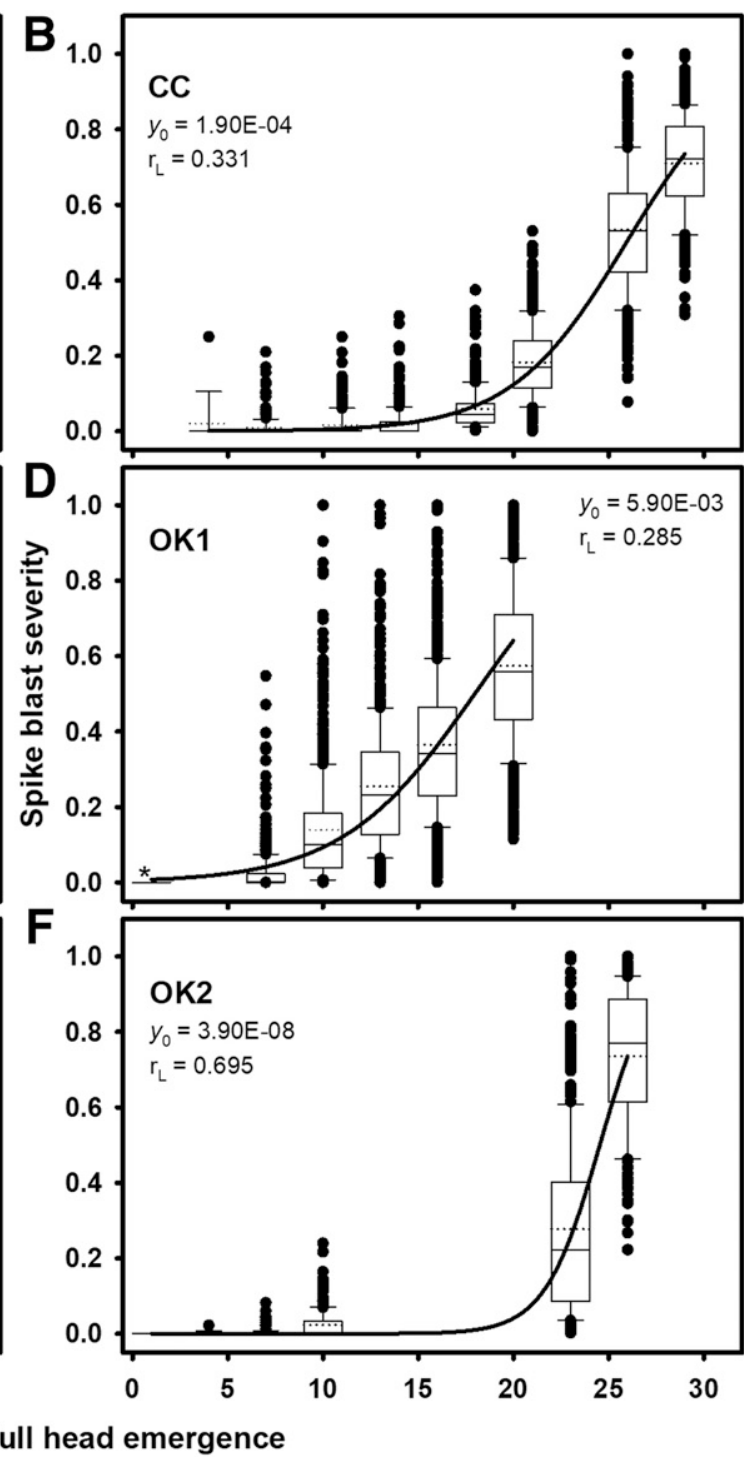
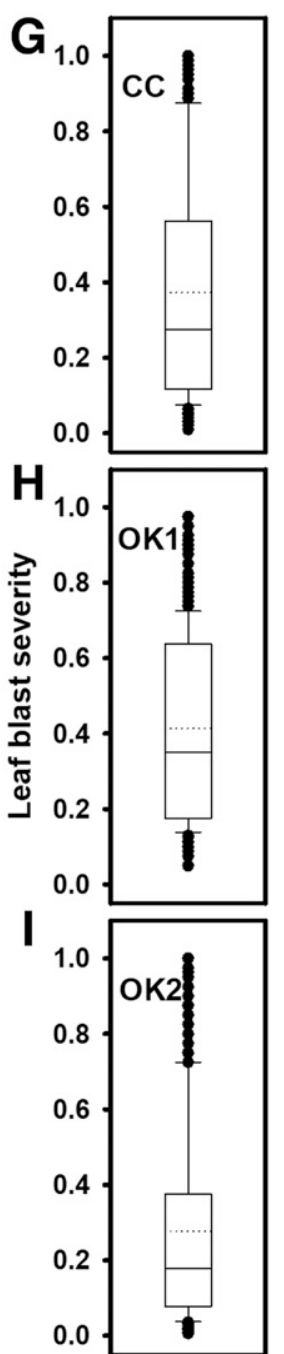

Fig. 2. Box plots showing the distribution of and temporal change in mean wheat spike blast incidence $(\mathbf{A}, \mathbf{C}$, and $\mathbf{E}$, proportion of diseased spike in a sample of $\geq 15$ spikes $)$ and severity (B, D, and F, mean proportion of bleached, discolored spikelets per spike) in naturally infected wheat fields at Cuatro Cañadas (CC; $\left.17^{\circ} 26.48^{\prime} \mathrm{S}, 62^{\circ} 35.91^{\prime} \mathrm{W}\right), \mathrm{Okinawa} 1$ (OK1; $\left.17^{\circ} 14.55^{\prime} \mathrm{S}, 62^{\circ} 53.35^{\prime} \mathrm{W}\right)$, and Okinawa 2 (OK2; $17^{\circ} 20.41^{\prime} \mathrm{S}, 62^{\circ} 52.60^{\prime} \mathrm{W}$ ) near Santa Cruz de la Sierra, Bolivia. G, H, and I, Distribution of mean leaf blast severity on the flag leaf at 21,20, and 23 days after full head emergence (Feekes growth stage 10.5) at CC, OK1, and OK2, respectively. Broken and solid lines in each box represent means and medians, respectively, and the top and bottom lines of the box represent the 75th and 25th percentiles of the data, respectively. Vertical bars extending above and below the boxes represent the fifth and 95th percentiles, and symbols represent outliers. Progress curves are for estimated predicted incidence and severity from the fit of the logistic population growth models to the means of the distributions at each assessment time after Feekes 10.5. Parameters are in Table 2. * Because the initial level of disease was extremely low at the time of the first assessment at OK1, mean intensity was estimated based on visual inspections and images of the plots instead of assessments of individual spikes. 
head emergence was significantly higher at OK1 (70\%) than at CC $(16 \%)$ and OK2 (8\%).

Time-to-event analysis. Estimated time to 10, 15, and 20\% spike blast severity. The time it took for $\mathrm{SEV}\left(t_{\mathrm{s}}\right)$ to reach certain thresholds $(10,15$, and $20 \%)$, estimated with the parameters from the logistic model, varied between locations and between sampling sites within locations. For instance, at OK2 it took an estimated 11 to 25 days for severity to reach $10 \%\left(t_{10}\right)$, whereas at OK1 and CC that same level of severity was reached between 1 and 19 days and 6 and 26 days, respectively (Fig. 3). Mean $t_{10}$ was 19, 10, and 22 days at $\mathrm{CC}$, OK1, and KO2, respectively (Fig. 3A, D, and G). The corresponding mean $t_{15}$ and $t_{20}$ values were 21,12 , and 23 days (Fig. $3 \mathrm{~B}, \mathrm{E}$, and $\mathrm{H}$ ) and 22, 13, and 23 days (Fig. 3C, F, and I); it took about 10 fewer days for a given threshold to be reached at OK1 compared with OK2 and CC.

Survivor function and estimated survival probability. The probabilities of SEV reaching $y_{10}, y_{15}$, or $y_{20}(10,15$, or $20 \%)$ between 1 and 21 days after full head emergence (i.e., 1 - "survival" probability) were estimated and formally compared between locations through survival (time-to-event) analysis. At OK1, the SEV thresholds were reached at $>98 \%$ at the sampling sites by 21 days after Feekes 10.5 (i.e., 1 - survival $\geq 0.98$ ) (Table 3 ). The probability of reaching the thresholds earlier in the epidemic (e.g., 14 days after Feekes 10.5$)$ was also fairly high $(0.55$ to 0.85$)$ at OK1 compared with the other two locations (Table 3). The opposite trend was observed at OK2, where a large percentage ( 83 to $96 \%$ ) of the observations were censored at 21 days. In other words, probabilities of survival (not reaching the threshold by 21 days after Feekes 10.5) were between 0.83 and 0.96 (Fig. 4A, C, and E), equivalent to probability of reaching $y_{S}$ between $0.04(1-0.96)$ and 0.17 (1-0.83). Probabilities of reaching $y_{10}, y_{15}$, or $y_{20}$ by 21 days after full head emergence were intermediate $(0.73,0.46$, and 0.28 , respectively) at CC (Table 3).

Effect of location and leaf blast severity on spike blast survivor function. For all but one pairwise comparison between locations, the survivor functions were significantly different between locations for $y_{10}, y_{15}$, or $y_{20}(P<0.05$, Table 4$)$. The effect of LEAF (as a categorical variable) on spike blast time to event was statistically significant $(P>0.05)$ at $\mathrm{OK} 1$ for all three thresholds, only for $y_{15}$ at $\mathrm{OK} 2$, but was not statistically significant for any of the thresholds at CC (Table 4 and Fig. 4B, D, and F). The negative signs of the log-rank test statistics in Table 4 indicate that as LEAF increased, time to $y_{10}, y_{15}$, or $y_{20}$ decreased. As shown in Figure 4B, D, and F, the probabilities of spike blast not reaching $y_{10}, y_{15}$, or $y_{20}$ were highest $(0.25$,
$10 \%$ spike blast severity

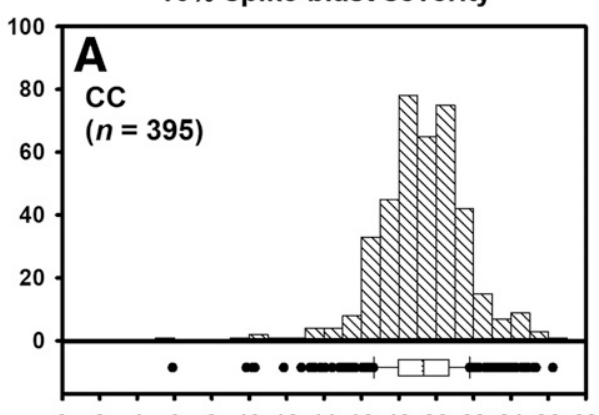

$\begin{array}{llllllllllllllll}0 & 2 & 4 & 6 & 8 & 10 & 12 & 14 & 16 & 18 & 20 & 22 & 24 & 26 & 28 & 0\end{array}$

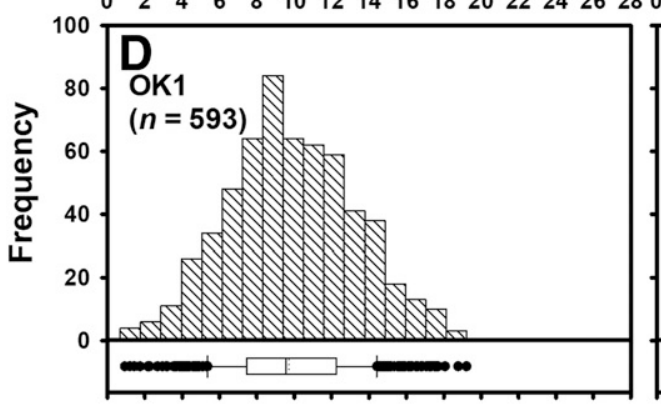

$\begin{array}{lllllllllllllll}0 & 2 & 4 & 6 & 8 & 10 & 12 & 14 & 16 & 18 & 20 & 22 & 24 & 26 & 28\end{array}$

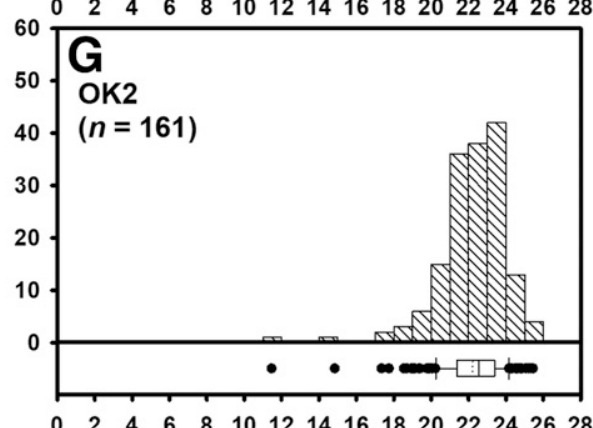

$\begin{array}{lllllllllllllll}0 & 2 & 4 & 6 & 8 & 10 & 12 & 14 & 16 & 18 & 20 & 22 & 24 & 26 & 28\end{array}$
$15 \%$ spike blast severity
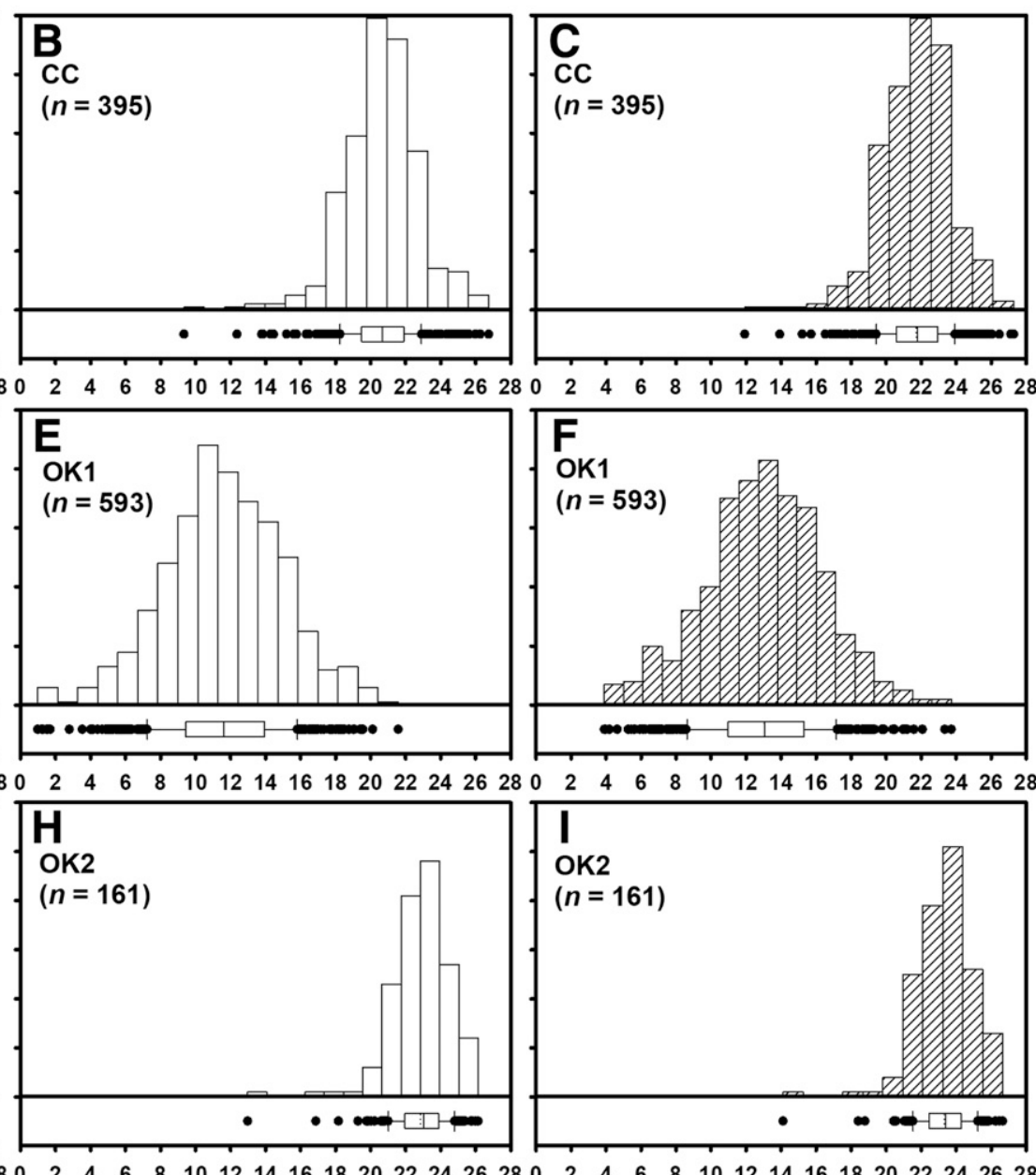

Days after full head emergence
$20 \%$ spike blast severity

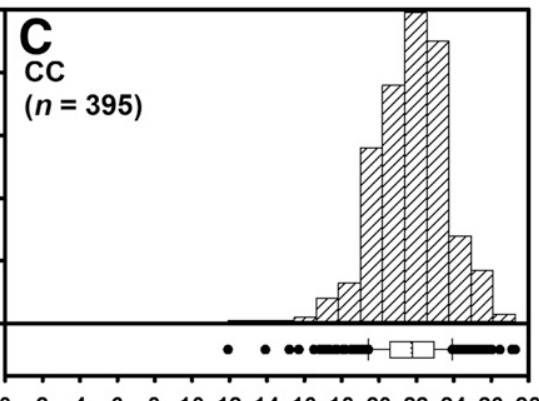

$\begin{array}{llllllllllllll}2 & 4 & 6 & 8 & 10 & 12 & 14 & 16 & 18 & 20 & 22 & 24 & 26 & 28\end{array}$

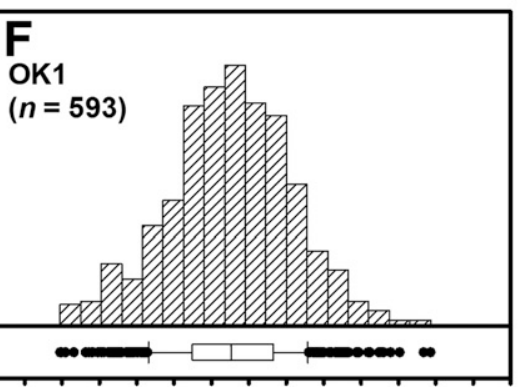

Fig. 3. Histograms and box plots showing the distribution of time (days after Feekes growth state 10.5, full head emergence) to 10 (A, D, and G), 15 (B, E, and H), and $20 \%$ (C, F, and I) wheat blast severity (mean proportion of bleached, discolored spikelets per spike) estimated with Equation 3 by using parameters from the fit of logistic population growth models to data collected from naturally infected wheat fields at Cuatro Cañadas (CC; $\left.17^{\circ} 26.48^{\prime} \mathrm{S}, 62^{\circ} 35.91^{\prime} \mathrm{W}\right)$, Okinawa 1 (OK1; $\left.17^{\circ} 14.55^{\prime} \mathrm{S}, 62^{\circ} 53.35^{\prime} \mathrm{W}\right)$, and Okinawa 2 (OK2; $17^{\circ} 20.41^{\prime} \mathrm{S}, 62^{\circ} 52.60^{\prime} \mathrm{W}$ ) near Santa Cruz de la Sierra, Bolivia. Broken and solid lines in each box plot represent means and medians, respectively, and the left and right edges of the box represent the 25 th and 75 th percentiles of the data, respectively. Whiskers extending beyond the boxes represent the fifth and 95 th percentiles, whereas circles represent outliers. 
0.44 , and 0.67 , respectively) when LEAF was $<25 \%$ and lowest $(0.05,0.09,0.18$, respectively) what LEAF was $>50 \%$. In other words, when LEAF was $\geq 50 \%$, the probability of SEV reaching $20 \%$ by 21 days after Feekes 10.5 was 0.82 ; when LEAF was between 25 and $<50 \%$, the probability was 0.62 ; and when LEAF was $<25 \%$, the probability was only 0.33 .

Through Cox nonproportional hazard regression analysis, hazard ratios (HRs) were estimated as measures of the magnitude of location and LEAF effects on the likelihood of SEV reaching 10, 15, or $20 \%$ $\left(y_{10}, y_{15}\right.$, or $\left.y_{20}\right)$ by 21 days after Feekes 10.5 . An HR value of 1 means that the event $\left(y_{10}, y_{15}\right.$, or $y_{20}$ being reached) is equally likely between the groups being compared, HR $>1$ means that the event is less likely in the reference group that in the group being compared, and $\mathrm{HR}<1$ means the opposite. For comparisons between pairs of locations, the tested null hypothesis was $\mathrm{HR}=1$. Using $\mathrm{OK} 1$ as the reference, the HRs were all $<1$, particularly for comparisons between OK1 and CC. This means that the probabilities of SEV reaching the thresholds were higher for OK1 than CC. For instance, the chance of SEV reaching 10,15 , or $20 \%$ by day 21 after heading was $>100$ times greater at OK1 than at CC. The chance of SEV reaching 10
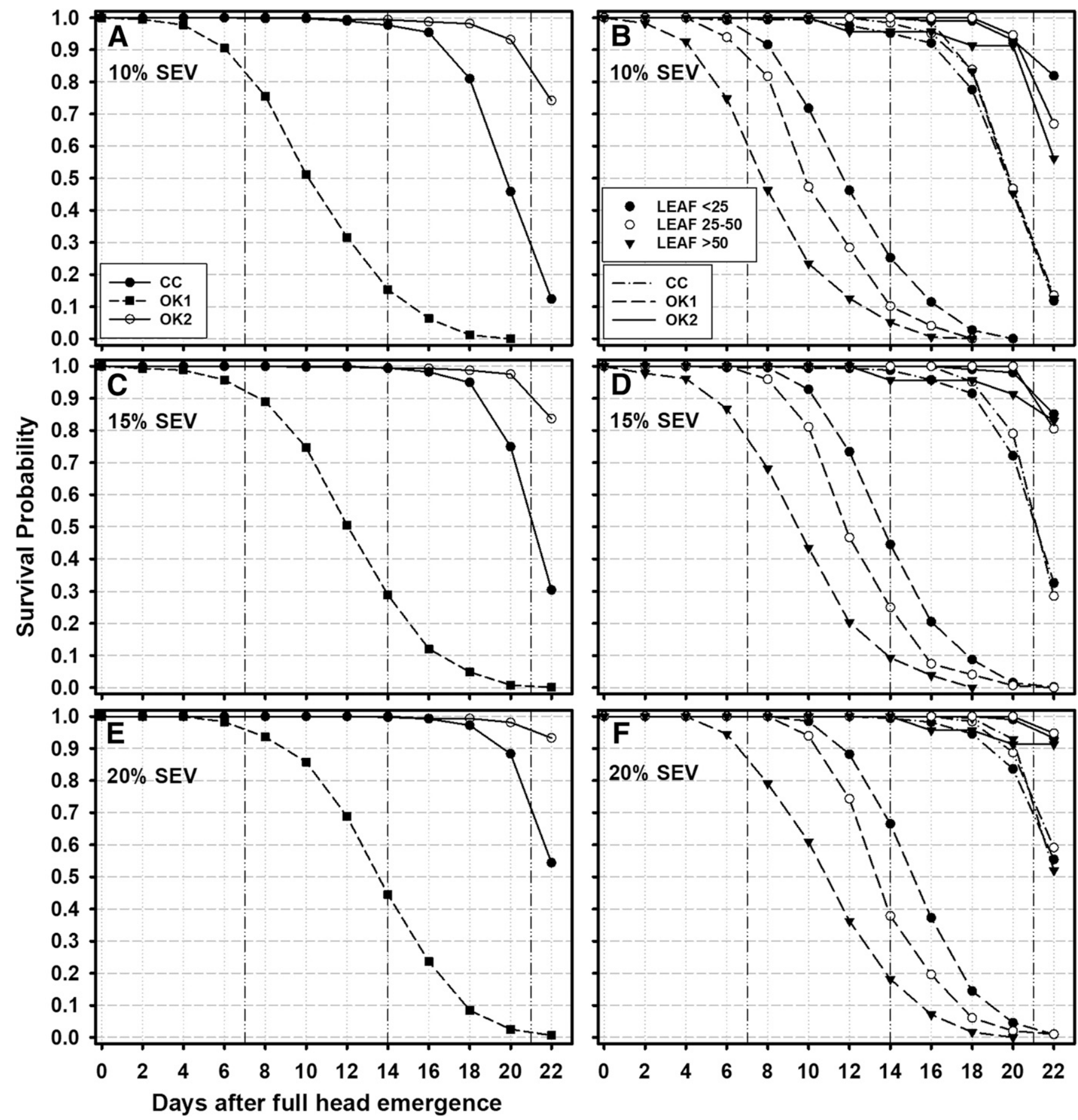

Fig. 4. Survival curves for time to $10(\mathbf{A}$ and $\mathbf{B}), 15(\mathbf{C}$ and $\mathbf{D})$, and $20 \%$ (E and $\mathbf{F}$ ) wheat spike blast severity (SEV, mean proportion of bleached, discolored spikelets per spike) for naturally infected wheat fields in Cuatro Cañadas (CC; $\left.17^{\circ} 26.48^{\prime} \mathrm{S}, 62^{\circ} 35.91^{\prime} \mathrm{W}\right)$, Okinawa 1 (OK1; $\left.17^{\circ} 14.55^{\prime} \mathrm{S}, 62^{\circ} 53.35^{\prime} \mathrm{W}\right)$, and Okinawa 2 (OK2; $\left.17^{\circ} 20.41^{\prime} \mathrm{S}, 62^{\circ} 52.60^{\prime} \mathrm{W}\right)$ near Santa Cruz de la Sierra, Bolivia, and for leaf blast severity (LEAF; percentage flag leaf area diseased at 21 day after Feekes 10.5 ) categories (LEAF $<25 \%$, LEAF 25 to $<50 \%$, and $\mathrm{LEAF} \geq 50 \%$ ) at each location. For the purpose of these analyses, an event was considered to have occurred if the specific SEV $(10,15$, or $20 \%)$ was reached or exceeded at 21 days after full head emergence (Feekes 10.5). Lines represent estimated probabilities of the event not occurring; in survival analysis terms, this would be equivalent to the probability of "surviving" the event. 
and $15 \%$ was $>26$ and 7 times greater at $\mathrm{OK} 1$ than at OK2. Contrast between OK1 and OK2 for $y_{20}$ was not statistically significant $(P>$ $0.05)$. For LEAF as a continuous covariate, for every $5 \%$ increase in severity, the likelihood of SEV reaching 10,15 , and $20 \%$ by 21 days after Feekes 10.5 increased by 31,43 , and $55 \%$, respectively (HRs of 1.31, 1.43, and 1.55; Fig. 5).

\section{Discussion}

In this study, we successfully quantified the temporal development of wheat spike blast at three field locations in the Santa Cruz de la Serra region of Bolivia where the disease is endemic, in a year (2015) during which a strong El Niño-Southern Oscillation events led to conditions being conducive (rainfall and temperatures between 18 and $25^{\circ} \mathrm{C}$ during anthesis, followed by warm, humid days) to disease development (Cardoso et al. 2008; Kohli et al. 2011). Although less favorable weather in 2016 prevented the experiments from being repeated for a second growing season, the fact that plots were planted on different dates and growing conditions varied between the locations in the first season meant that the crop and, consequently, the epidemics developed under different conditions at the three locations, allowing us to make acceptable comparisons. In all three fields, disease intensity increased over time for 25 to 30 days before reaching or approaching $100 \%$ mean incidence and, in all cases, without reaching mean severity of $100 \%$ at the time of the final assessment. The results of the temporal increase in spike blast intensity are consistent with those reported by Gomes et al. (2019), Gongora-Canul et al. (2020), and Rios et al. (2016). Of the population growth models fitted to the data, the exponential and logistic were the most appropriate for describing the temporal change in incidence and severity. However, from a biological standpoint, as discussed by Madden et al. (2007), given that the same cohort of wheat spikes of a fixed size was rated at each time, it is unrealistic to expect spike blast to increase indefinitely over time, as suggested by the exponential model. So although the simplified exponential representation of spike blast temporal dynamics would probably be appropriate for situations in which blast intensity is low (Madden et al. 2007), we opted to focus on the more biologically relevant logistic model (of equally good fit). This model describes epidemics that increase over time and then level off as healthy individuals and host tissues become limiting. The exponential model is a special case of the logistic model.

The fact that the logistic model was generally the most appropriate for describing wheat spike blast epidemics at all three locations and that it provided very good fit to both incidence and severity data allowed us to make several interpretations about spike blast epidemiology. For instance, the fit of this model is consistent with a polycyclic-like disease. This finding suggests that primary infections from resident inoculum within or outside the fields, the production and spread of inoculum during the season, and secondary infection of healthy spikes drive epidemics. However, the logistic shape of the disease progress curves is also consistent with a monocyclic disease in which the rate parameter $\left(r_{M}\right)$ increases over time (Madden et al. 2007). This occurs when either the primary (and only) inoculum for spike infection increases monotonically over time or the efficiency with which this inoculum causes infection increases over time (e.g., because of increasing favorability of the environment for dispersal or infection). If overwintering structures were the main source of inoculum and $r_{M}$ were constant, the monomolecular model probably would have provided a better fit than was observed in the study. The spike blast incidence progress curves support the idea of a monocyclic epidemic with increasing $r_{M}$, because there would have been insufficient time for infected spikes to produce inoculum that would infect other spikes (on primary tillers) in the epidemic. One may argue that the asynchronous heading observed in this study, a common characteristic of wheat crops that results largely from secondary tiller development after primary tillers are produced, and infection of the later-produced secondary spikes could have contributed to the temporal change in incidence. However, this was unlikely to occur over the entire duration of the epidemic (20+ days after Feekes 10.5), as was the case here.

We can refer to spike blast as a polycyclic-like disease because we do not have data showing that spores spreading from diseased to healthy spikes were the primary drivers of the epidemic, a necessary condition stipulated in the classic definition of a polycyclic disease (Madden et al. 2007). Throughout the epidemic, spores infecting the spikes could have come from overwintering and external sources or from sporulating leaves, as hypothesized by Cruz et al. (2015), Gongora-Canul et al. (2020), and Cruppe (2020). The shape of the spike blast progress curves could directly reflect the temporal development of disease on the leaves, with spores dispersing from the sporulating leaf lesions to the spike. This is fully consistent with a monocyclic process for spike disease incidence (and possibly severity) with increasing $r_{M}$. The logistic (or any polycyclic) population growth of leaf blast severity would mean that inoculum was increasing over time, infecting spikes (even at fixed infection efficacy of inoculum), and leading to increasing $r_{M}$. This implication was a motivation for characterizing spike blast epidemics with a survival analysis that accounted for leaf disease severity. Moreover, for spike blast severity (equivalent to incidence of diseased spikelets), a temporal increase in the mean proportion of diseased spikelets per spike could have resulted from spread of the fungus within the spike (colonization), even if new infections of spikelets from spores produced on other spikes did not occur. Working in a closed system in which applied spores were the only source of inoculum, Mills et al. (2020) clearly showed through point inoculations (Andersen et al. 2015) of

Table 4. Summary statistics from log-rank tests of the null hypotheses of no difference in survivor function between pairs of locations and no effect of leaf blast severity on spike blast survivor function at each location ${ }^{\mathrm{a}}$

\begin{tabular}{|c|c|c|c|c|c|c|c|}
\hline \multirow[b]{2}{*}{ SEV } & \multicolumn{2}{|c|}{ Location effect $^{\mathbf{b}}$} & \multicolumn{5}{|c|}{ Leaf blast severity effect ${ }^{c}$} \\
\hline & Comparison & $P$ & Location & Test statistic & SE & $x^{2}$ & $P$ \\
\hline \multirow[t]{3}{*}{$10 \%$} & $\mathrm{CC}$ versus $\mathrm{OK} 1$ & $<0.001$ & $\mathrm{CC}$ & -0.48 & 4.39 & 0.01 & 0.913 \\
\hline & $\mathrm{CC}$ versus $\mathrm{OK} 2$ & 0.048 & OK1 & -70.44 & 5.07 & 193.20 & $<0.001$ \\
\hline & OK1 versus OK2 & $<0.001$ & OK2 & -2.62 & 1.12 & 5.47 & 0.019 \\
\hline \multirow[t]{3}{*}{$15 \%$} & $\mathrm{CC}$ versus OK1 & $<0.001$ & $\mathrm{CC}$ & -0.69 & 3.68 & 0.04 & 0.851 \\
\hline & $\mathrm{CC}$ versus $\mathrm{OK} 2$ & 0.452 & OK1 & -75.44 & 5.02 & 225.90 & $<0.001$ \\
\hline & OK1 versus OK2 & $<0.001$ & OK2 & -0.41 & 0.84 & 0.23 & 0.630 \\
\hline \multirow[t]{3}{*}{$20 \%$} & $\mathrm{CC}$ versus $\mathrm{OK} 1$ & $<0.001$ & $\mathrm{CC}$ & -0.33 & 2.79 & 0.01 & 0.906 \\
\hline & $\mathrm{CC}$ versus $\mathrm{OK} 2$ & $<0.001$ & OK1 & -76.96 & 4.96 & 240.50 & $<0.001$ \\
\hline & OK1 versus OK2 & $<0.001$ & OK2 & -0.53 & 0.56 & 0.89 & 0.345 \\
\hline
\end{tabular}

a $\mathrm{SEV}=$ mean spike blast severity (mean proportion of diseased spikelets per spike) at 21 days after full head emergence (Feekes 10.5 ) used as the threshold/event for time-to-event analysis; CC, OK1, and OK2 are Cuatro Cañadas, Okinawa 1, and Okinawa 2, respectively, the three levels of the categorical variable field location.

b Pairwise comparison of survivor function and level of significance $(P)$ adjusted for multiple comparisons via the Tukey-Kramer method.

${ }^{\mathrm{c}}$ Log-rank test statistic, standard error (SE), $\chi^{2}$ value, and level of significance $(P)$ from tests of the null hypothesis that leaf blast severity at 21 days after Feekes 10.5 is unrelated to spike blast survival time. 
wheat spikes with an isolate of MoL that severity increased over time in a manner consistent with a polycyclic disease.

Although the logistic model was considered appropriate for describing epidemics at all three locations, model parameters differed, causing the curves to shift between locations. That is, the period with highest absolute rate of disease increase, $d y / d t$, occurred much later for spike severity at OK2 (such that $y$ was not close to the maximum by the last assessment time) and earliest at OK1. This reflects the fact that OK2 had the highest $r_{L}$ and lowest $y_{0}$, and OK1 had the highest $y_{0}$ and lowest $r_{L}$ for spike severity. CC was intermediate. The same trends in the parameter estimates were found for spike incidence, although the overall INC was much higher than SEV, which is a well-known phenomenon (Paul et al. 2005). Differences between the locations were probably caused by differences in weather conditions, crop development, and inoculum abundance and infection efficiency. Summaries for temperature and RH were very similar for OK1 and OK2, but the amounts, frequency, and distribution of rainfall differed between the two locations. At OK1, it rained on 4 of the first 7 days after initial heading, for a total precipitation of $64 \mathrm{~mm}$, whereas at OK2 it remained rain free during the first 11 days after initial heading and then rained on 6 of the next 8 days, for a total of $126 \mathrm{~mm}$. At both locations, the rain events occurred during the week before the highest absolute rate of disease increase (the inflection point) occurred, thus explaining why incidence and severity peaked much later at OK2 than at OK1.

Differences in inoculum density, caused in part by inoculum produced on leaves, and to a lesser extent heading synchrony, could have also been the reasons for differences in spike blast development between OK1 and OK2. For instance, during the early stages of crop development (before heading), foci of naturally infected tillers with sporulating lesions were observed in both fields. However, these inoculum foci were larger and more abundant at OK1, the location with the highest mean leave blast severity, than at OK2 (J. D. Salgado, personal communication). Higher levels of in-field inoculum combined with rainfall during heading were probably the reasons for higher $y_{0}$ at OK1 compared with OK2. Higher $y_{0}$ coupled with more synchronized heading and the absence of later-season rainfall could have resulted in lower $r_{\mathrm{L}}$ at OK1 than at OK2. With the very low $y_{0}$ at $\mathrm{OK} 2$, predicted disease severity reached only 0.75 by the last assessment (26 days after heading), even with the very high $r_{\mathrm{L}}$. A similar set of arguments could be used to explain differences in parameter estimates and, consequently, spike blast progress between $\mathrm{OK} 1$ and $\mathrm{CC}$ and between $\mathrm{OK} 2$ and $\mathrm{CC}$. For instance, as was the case at OK1, it also rained during the first week of heading at $\mathrm{CC}$, but only in a single event totaling $70 \mathrm{~mm}$. This rainfall would have stimulated inoculum production and, consequently, higher initial blast intensity $\left(y_{0}\right)$ at $\mathrm{CC}$ than at $\mathrm{OK} 2$, where it did not rain during early heading. However, frequent and abundant late-season rainfall coupled with synchronized heading and an abundance of healthy spikes at OK2 (because of significantly lower $y_{0}$ and retarded disease progress during the first

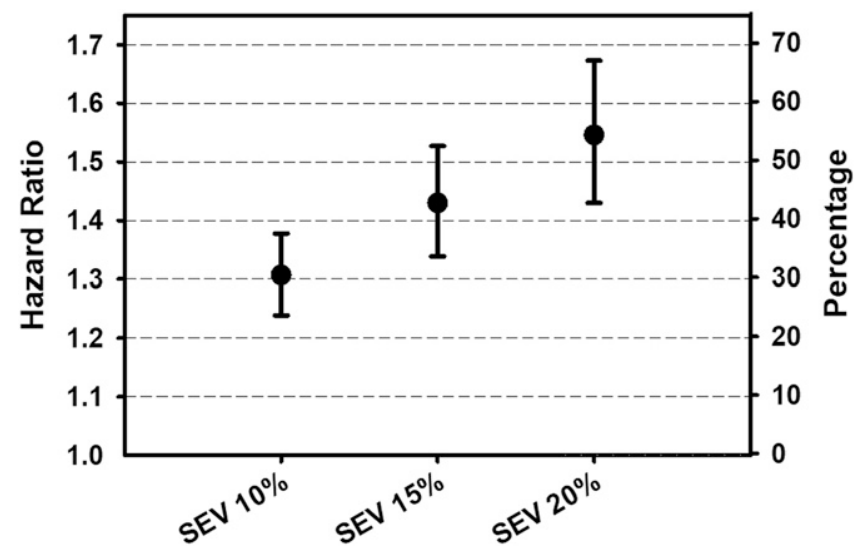

Fig. 5. Hazard ratios from Cox nonproportional hazard regression analyses of associations between wheat leaf blast severity (mean percentage flag leaf area diseased at 21 days after Feekes 10.5) and time to 10, 15, and 20\% spike blast severity (SEV, mean proportion of bleached, discolored spikelets per spike).
3 weeks after heading) would have resulted in the highest absolute rate of increase in spike blast severity occurring much later at OK2 than at $\mathrm{CC}$, where it did not rain late in the season.

By definition, $y_{0}$ and $r_{\mathrm{L}}$ both influenced time to 10,15 , and $20 \%$ severity $\left(t_{\mathrm{S}}\right.$; Equation 3$)$, but sometimes differences in $y_{0}$ could override large differences in $r_{\mathrm{L}}$ between epidemics in the prediction of times to different severity thresholds. In the long run, epidemics characterized by the logistic model are more sensitive to the rate parameter than to $y_{0}$ (Madden et al. 2007); however, the orders-of-magnitude differences in $y_{0}$ (e.g., $10^{-8}$ to $10^{-3}$ for severity) between the locations were large enough to dominate in determining the time it took for spike blast to reach these low levels of severity. Although $r_{\mathrm{L}}$ for severity was significantly lower at OK1 than at OK2 and numerically lower than at $\mathrm{CC}$, the earlier establishment of blast at OK1 (higher $y_{0}$ ) than at OK2 and $\mathrm{CC}$ resulted in $t_{\mathrm{S}}$ (time to the 10,15 , and $20 \%$ severity thresholds) being about 10 to 12 days shorter at OK1 than at CC and OK2. When compared with $\mathrm{CC}$, the higher $r_{\mathrm{L}}$ at $\mathrm{OK} 2$ did compensate for the fact that $y_{0}$ was significantly lower, resulting in the two locations having very similar $t_{\mathrm{S}}$ values. The observed preheading sporulating leaf blast foci probably contributed to earlier spike blast establishment (higher $y_{0}$ ) and, consequently, shorter time to event at OK1 than at OK2 and CC. Although we were unable to deploy spore traps in our experiments, we did quantify spore density within plots before Feekes 10.5 through leaf washes and spore counts (Cruz et al. 2015) and found that 30 to 100 times more spores were present on plants with high leaf blast severity than on plants without leaf blast (C. D. Cruz, unpublished). Results from the survival analysis corroborated these observations and formally showed an association between leaf blast severity and spike blast survival/failure time at OK1 (i.e., the probability of spike blast "surviving" or reaching each threshold at a given time). The effect of leaf blast severity on spike blast time to event was statistically significant at $\mathrm{OK} 1$ for all $t_{\mathrm{S}}$, with the probability of the severity thresholds being reached at any given time increasing as leaf blast severity increased. This finding is consistent with the high $y_{0}$ in OK1. The nonproportional hazard model analysis may not have had sufficient precision to consistently detect leaf blast severity effects when $y_{0}$ was much lower than at OK1.

Wheat blast management in Bolivia and other parts of South America where the disease is endemic are not usually based on knowledge and understanding of disease epidemiology. For instance, there are no deployed disease forecasting or risk assessment tools to help guide fungicide applications or yield loss models from which economic injury levels or damage thresholds can be established. This may explain in part the inconsistency in results between fungicide trials in terms of efficacy (Cruz and Valent 2017; Cruz et al. 2019). Findings from the present study will be useful for developing and improving blast management guidelines, particularly if coupled with risk assessment and economic analysis models. For instance, in Bolivia, where some fields with $\geq 30 \%$ wheat blast severity are abandoned (J. Kiyuna, personal communication), results from our timeto-event analysis could be used to help guide fungicide application to reduce disease progress and minimize the risk of this decision threshold being reached. This application could be tailored to each field based on the specific characteristics of the epidemic. For instance, under conditions similar to those prevalent at OK1, with low $t_{S}$ values (e.g., 10 or $15 \%$ ), fields will have to be treated with an effective fungicide early enough to reduce the likelihood of these thresholds being reached through a reduction in $r_{L}$. Moreover, given the observed importance of $y_{0}$ and leaf blast severity for spike blast development, especially for some epidemics, strategies to reduce initial inoculum and even an early fungicide application to manage leaf blast would be of value for reducing the onset and severity of spike blast. These strategies could lead to critical thresholds being reached after grain fill is complete, as was the case at $\mathrm{OK} 2$ and $\mathrm{CC}$, thus reducing the impact of spike blast on grain yield. As Rios et al. (2016) demonstrated, spike blast severity at 10 days after anthesis has a stronger negative effect on grain yield than severity at 21 days after anthesis. Finally, one cannot rule out the possibility of the appropriate decision being to abandon a field in some cases; predictions of $t_{S}$ would give guidance in this regard, if coupled with an economic analysis. 


\section{Acknowledgments}

The authors thank Cooperativa Agropecuaria Integral Colonias Okinawa, Centro Tecnológico Agropecuario en Bolivia, and Asociación de Productores de Oleaginosas y Trigo for supporting the experiments conducted in Bolivia. The authors acknowledge Diego F. Baldelomar, Javier Kiyuna, Maryluz Huainoca, and Juan Vasquez for their help with field activities.

\section{Literature Cited}

Allison, P. D. 2010. Survival Analysis Using the SAS System: A Practical Guide. 2nd ed. SAS Institute Inc., Cary, NC.

ANAPO. Asociación de Productores de Oleaginosas y Trigo. 2015. Recomendaciones Técnicas para el Cultivo de Trigo. ANAPO, Santa Cruz, Bolivia.

Andersen, K. F., Madden, L. V., and Paul, P. A. 2015. Fusarium head blight development and deoxynivalenol accumulation in wheat as influenced by post-anthesis moisture patterns. Phytopathology 105:210-219.

Barea, G. and Aguanta, G. 2012. Manual de Recomendaciones Técnicas: Cultivo de Trigo. Asociación de Productores de Oleaginosas y Trigo ANAPO, Santa Cruz de la Sierra, Bolivia..

Barea, G., and Toledo, J. 1996. Identificación y zonificación de piricularia o bruzone (Pirycylaria oryzae) en el cultivo del trigo en el dpto. de Santa Cruz. Pages 76-86 in: Informe Técnico. Proyecto de Investigación Trigo. CIAT, Santa Cruz, Bolivia.

Bland, J. M., and Altman, D. G. 2004. The logrank test. BMJ 328:1073.

Breusch, T. S., and Pagan, A. R. 1979. A simple test for heteroskedasticity and random coefficient variation. Econometrica 47:1287-1294.

Cabrera, M., and Gutiérrez, S. 2007. Primer Registro de Pyricularia grisea en Cultivos de Trigo del NE de Argentina. Depto. Protección Vegetal, Facultad de Ciencias Agrarias, UNNE, Corrientes, Argentina.

Cardoso, C. A. de A., Reis, E. M., and Moreira, E. N. 2008. Development of a warning system for wheat blast caused by Pyricularia grisea. Summa Phytopathol. 34:216-221.

Ceresini, P. C., Castroagudín, V. L., Rodrigues, F. Á., Rios, J. A., Aucique-Pérez, C. E., Moreira, S. I., Alves, E., Croll, D., and Maciel, J. L. N. 2018. Wheat blast: past, present, and future. Annu. Rev. Phytopathol. 56:427-456.

Ceresini, P. C., Castroagudín, V. L., Rodrigues, F. Á., Rios, J. A., Aucique-Pérez, C. E., Moreira, S. I., Croll, D., Alves, E., Carvalho, G., Maciel, J. L. N., and McDonald, B. A. 2019. Wheat blast: from its origins in South America to its emergence as a global threat. Mol. Plant Pathol. 20:155-172.

Cruppe, G. 2020. Wheat blast management through identification of novel sources of genetic resistance and understanding of disease dynamics. Ph.D. dissertation, Department of Plant Pathology, Kansas State University, Manhattan, KS.

Cruz, C. D., Bockus, W. W., Stack, J. P., Tang, X., Valent, B., Pedley, K. F., and Peterson, G. L. 2012. Preliminary assessment of resistance among U.S. wheat cultivars to the Triticum pathotype of Magnaporthe oryzae. Plant Dis. 96:1501-1505.

Cruz, C. D., Kiyuna, J., Bockus, W. W., Todd, T. C., Stack, J. P., and Valent, B. 2015. Magnaporthe oryzae conidia on basal wheat leaves as a potential source of wheat blast inoculum. Plant Pathol. 64:1491-1498.

Cruz, C. D., Peterson, G. L., Bockus, W. W., Kankanala, P., Dubcovsky, J., Jordan, K. W., Akhunov, E., Chumley, F., Baldelomar, F. D., and Valent, B. 2016. The 2NS translocation from Aegilops ventricosa confers resistance to the Triticum Pathotype of Magnaporthe oryzae. Crop Sci. 56:990-1000.

Cruz, C. D., Santana, F., Todd, T. C., Maciel, J., Kiyuna, J., Baldelomar, D., Cruz, A. P., Lau, D., Seixas, C., Goulart, A., Sussel, A., Schipanski, C. A., Chagas, D. F., Coelho, M., Dalla Nora Montecelli, T., Utiamada, C., Custódio, A. P., Rivadeneira, M. G., Bockus, W. W., and Valent, B. 2019. Multi-environment assessment of fungicide performance for managing wheat head blast (WHB) in Brazil and Bolivia. Trop. Plant Pathol. 44:183-191.

Cruz, C. D., and Valent, B. 2017. Wheat blast disease: danger on the move. Trop. Plant Pathol. 42:210-222.

Cruz, M. F. A., Prestes, A. M., Maciel, J. L. N., and Scheeren, P. L. 2010. Partial resistance to blast on common and synthetic wheat genotypes in seedling and in adult plant growth stages. Trop. Plant Pathol. 35:24-31.

Derrick, B., Toher, D., and White, P. 2016. Why Welch's test is type I error robust. Quant. Methods Psychol. 12:30-38.

Durbin, J., and Watson, G. S. 1950. Testing for serial correlation in least squares regression, I. Biometrika 37:409-428.

Farman, M., Peterson, G., Chen, L., Starnes, J., Valent, B., Bachi, P., Murdock, L., Hershman, D., Pedley, K., Fernandes, J. M., and Bavaresco, J. 2017. The lolium pathotype of Magnaporthe oryzae recovered from a single blasted wheat plant in the United States. Plant Dis. 101:684-692.

Godfrey, L. G. 1978a. Testing against general autoregressive and moving average error models when the regressors include lagged dependent variables. Econometrica 46:1293-1301.

Godfrey, L. G. 1978b. Testing for higher order serial correlation in regression equations when the regressors include lagged dependent variables. Econometrica 46:1303-1310.
Goel, M. K., Khanna, P., and Kishore, J. 2010. Understanding survival analysis: Kaplan-Meier estimate. Int. J. Ayurveda Res. 1:274-278.

Gomes, D. P., Rocha, V. S., Rocha, J. R. A. S. C., Souza, M. A., and Pereira, O. L. 2019. Progresso temporal da brusone do trigo em função do inóculo primário da aplicação de fungicida e da resistência dos genótipos. Summa Phytopathol. 45:50-58.

Gongora-Canul, C., Salgado, J., Singh, D., Cruz, A., Cotrozzi, L., Couture, J. J., Rivadeneira, M. G., Cruppe, G., Valent, B., Todd, T., Poland, J., and Cruz, C. D. 2020. Temporal dynamics of wheat blast epidemics and agreement between remotely sensed data measurements and visual estimations of wheat spike blast (WsB) under field conditions. Phytopathology 110:393-405.

Goulart, A. C. P., Sousa, P. G., and Urashima, A. S. 2007. Danos em trigo causados pela infecção de Pyricularia grisea. Summa Phytopathol. 33:358-363.

Igarashi, S. 1990. Update on wheat blast (Pyricularia oryzae) in Brazil. Pages 480-483 in: Wheat for the Nontraditional Warm Areas: A Proceedings of the International Conference. D. A. Saunders, ed. CIMMYT, Foz do Iguaçu, Brazil

Igarashi, S., Utiamada, C. M., Igarashi, L. C., Kazuma, A. H., and Lopes, R. S. 1986. Pyricularia em trigo. 1. Ocorrência de Pyricularia sp. no estado do Paraná. Fitopatol. Bras. 11:351-352.

Kaplan, E. L., and Meier, P. 1958. Nonparametric estimation from incomplete observations. J. Am. Stat. Assoc. 53:457-481.

Kohli, M. M., Mehta, Y. R., Guzman, E., Viedma, L., and Cubilla, L. E. 2011 Pyricularia blast: a threat to wheat cultivation. Czech J. Genet. Plant Breed. 47:S130-S134.

Large, E. C. 1954. Growth stages in cereals illustration of the Feekes scale. Plant Pathol. 3:128-129.

Lima, M. 2004. Giverela ou brusone? Orientações para indentificação correta dessas enfermidades em trigo e em cevada. Embrapa Trigo Documentos online, 40. http://www.cnpt.embrapa.br/biblio/do/p_do40.pdf

Madden, L. V., and Hughes, G. 1995. Plant disease incidence: distributions, heterogeneity, and temporal analysis. Annu. Rev. Phytopathol. 33:529-564.

Madden, L. V., Hughes, G., and van den Bosch, F. 2007. The Study of Plant Disease Epidemics. American Phytopathological Society Press, St. Paul, MN.

Malaker, P. K., Barma, N. C. D., Tiwari, T. P., Collis, W. J., Duveiller, E., Singh, P. K., Joshi, A. K., Sigh, R. P., Braun, H. J., Peterson, G. L., Pedley, K. F., Farman, M. L., and Valent, B. 2016. First report of wheat blast caused by Magnaporthe oryzae pathotype Triticum in Bangladesh. Plant Dis. 100:2330.

Martínez, S. I., Sanabria, A., Fleitas, M. C., Consolo, V. F., and Perelló, A. 2019. Wheat blast: aggressiveness of isolates of Pyricularia oryzae and effect on grain quality. J. King Saud Univ. Sci. 31:150-157.

Mills, K. B., Madden, L. V., and Paul, P. A. 2020. Quantifying the effects of temperature and relative humidity on the development of wheat blast incited by the Lolium pathotype of Magnapothe oryzae. Plant Dis. 104:2622-2633.

Nunes Nesi, C. N., Emiko Shimakura, S., Ribeiro, P. J., and May De Mio, L. L. 2013. Survival Analysis in Plant Pathology. IDESIA (Chile). 31:017-110.

Ojiambo, P. S., and Scherm, H. 2005. Survival analysis of time to abscission of blueberry leaves affected by Septoria leaf spot. Phytopathology 95:108-113.

Paul, P. A., El-Allaf, S. M., Lipps, P. E., and Madden, L. V. 2005. Relationships between incidence and severity of Fusarium head blight on winter wheat in Ohio. Phytopathology 95:1049-1060.

Prabhu, A. S., Filippi, M. C., and Castro, N. 1992. Pathogenic variation among isolates of Pyricularia oryzae affecting rice, wheat, and grasses in Brazil. Trop. Pest Manage. 38:367-371.

Rios, A., Debona, D., Duarte, H., and Rodrigues, F. 2013. Development and validation of a standard area diagram set to assess blast severity on wheat leaves. Eur. J. Plant Pathol. 136:603-611.

Rios, J. A., Rios, V. S., Paul, P. A., Souza, M. A., Araujo, L., and Rodrigues, F. A 2016. Fungicide and cultivar effects on the development and temporal progress of wheat blast under field conditions. Crop Prot. 89:152-160.

Sadat, A., and Choi, J. 2017. Wheat blast: a new fungal inhabitant to Bangladesh threatening world wheat production. Plant Pathol. 33:103-108.

Scherm, H., and Ojiambo, P. S. 2004. Applications of survival analysis in botanical epidemiology. Phytopathology 94:1022-1026.

Torres, G., Santana, F., Fernandes, J., and Só E Silva, M. 2009. Doenças da espiga causam perda de rendimento em trigo nos estados do Paraná, São Paulo e Mato Grosso do Sul. Emprapa Trigo. Comunicado Técnico online, 255. https:// www.infoteca.cnptia.embrapa.br/bitstream/doc/821793/1/pco255.pdf

Urashima, A. S. 2010. Wheat blast. Pages 22-23 in: Compendium of Wheat Diseases and Pests. W. W. Bockus, R. L. Bowden, R. M. Hunger, and T. D. Murray, eds. American Phytopathological Society Press, St. Paul, MN.

Waggoner, P. E. 1986. Progress curves of foliar diseases: Their interpretation and use. Pages 3-37 in: K. J. Leonard and W. E. Fry, eds. Plant Disease Epidemiology. Vol. 1. Population Dynamics and Management.Macmillan Publishing Co., New York, NY.

Welch, B. L. 1947. The generalization of "Student's" problem when several different population variances are involved. Biometrika 34: 28-35.

White, H. 1980. A heteroskedasticity-consistent covariance matrix estimator and a direct test for Heteroskedasticity. Econometrica 48:817-838. 